$$
\text { ماجستير هنسة ( قدرة ومكائن ) }
$$

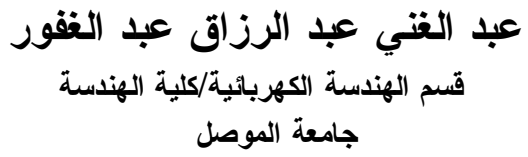

الخلاصة

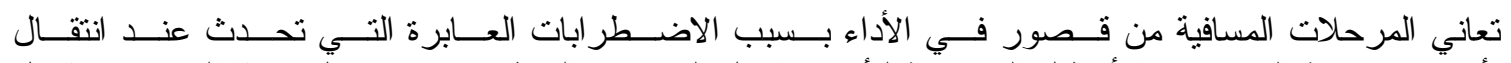

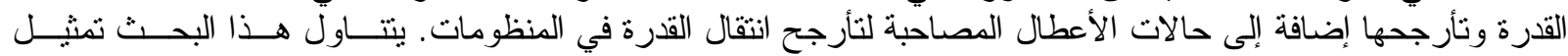

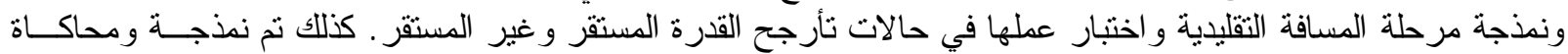

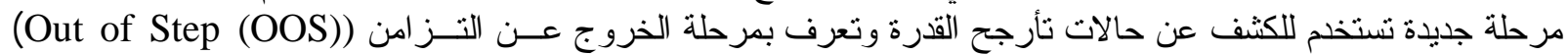

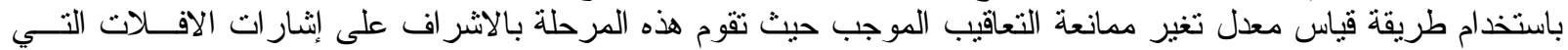

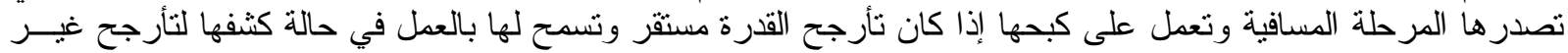

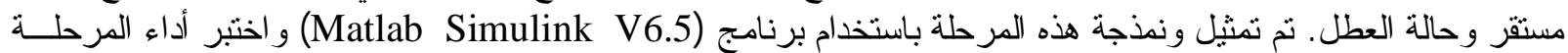

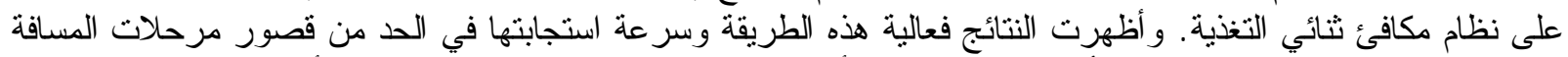
في الاستجابة للحالات العابرة بسبب تأرجح القدرة. كذللك أظهرت النتائج إمكانية عالية للتمييز بين الأعطال التي تحصل فئسي مدة التأرجح.

\title{
The Effect of Power Swing on Distance Relays Performance
}

\author{
Abdul Ghani A. Abdul Ghafoor \\ Electrical Engineering Department \\ College of Engineering \\ University of Mosul
}

\author{
Atheer Habash Abosh \\ Master of Power and Machines \\ Engineering
}

\begin{abstract}
The distance relay is suffering from under-reach in its performance. This is because of some transient disturbance, which may happen when the power flows and swings. Besides that the power swings as a consequence of some fault cases. In this paper a new distance relay has been suggested and modeled for detecting stable and unstable power swings.

This relay is known as out of step relay (OOS). The method employed is to measure the rate of change of the positive sequence impedance of the relay which supervise the trip signal that comes out of the distance relay. It allows the distance relay to work, if it detects an unstable power swing or a fault. On the other hand it blocks it if the power swing is stable. The new relay have been modeled and simulated using MATLAB-SIMULINK software programs.

The performance of this relay has been tested on an equivalent two sources system. The results prove that the suggested relay is active and fast. Thus overcoming the limitation of the distance relay in case of under-reach. The results also show that the new relay has the ability in discriminating between the types of faults, that occur during power swings.
\end{abstract}

Key Word: Power swing, Distance relay, Out of step protection technique. 


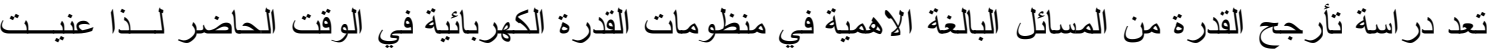

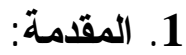

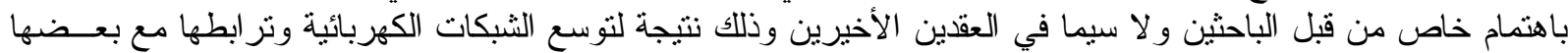
البعض بين بلدان العالم المختلفة.

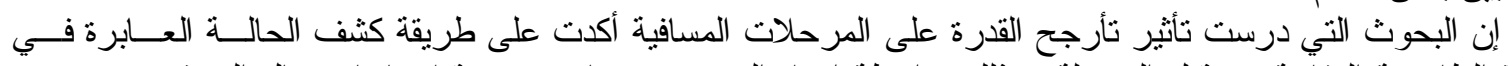

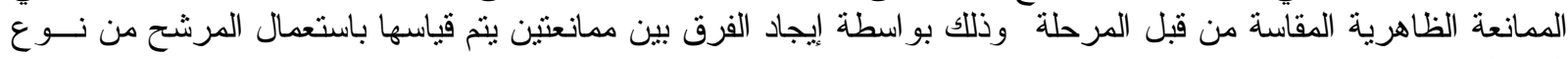

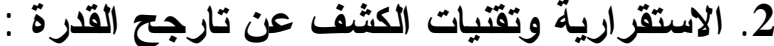

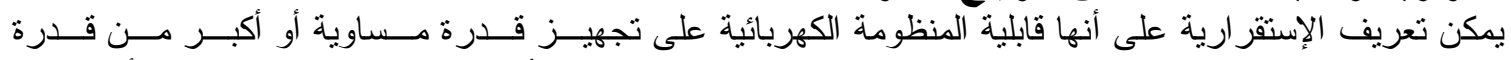

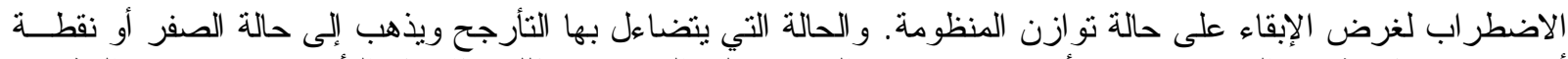

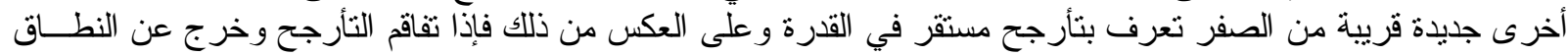

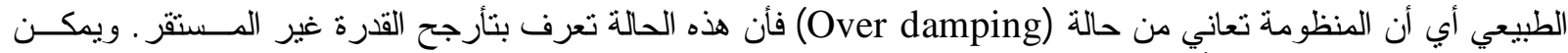

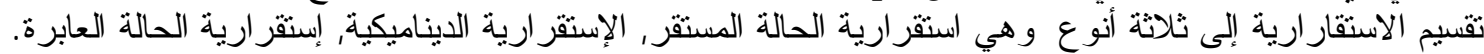

1-2: تأثير تأرجح القدرة على خطوط النقل ومرحلات النظام [1]]:

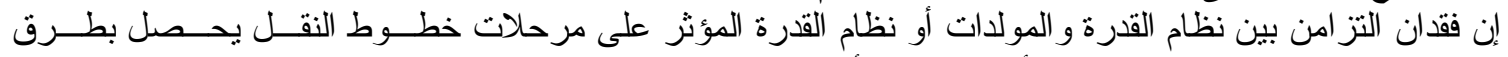

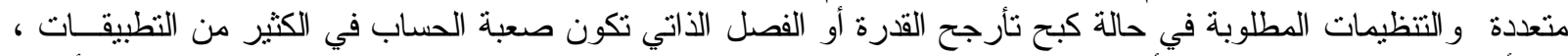

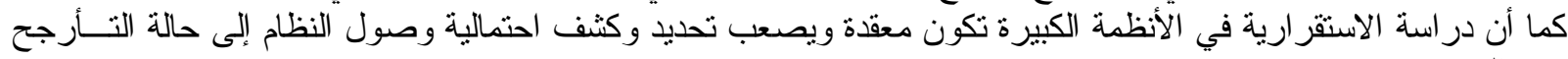
غير المستقرة.

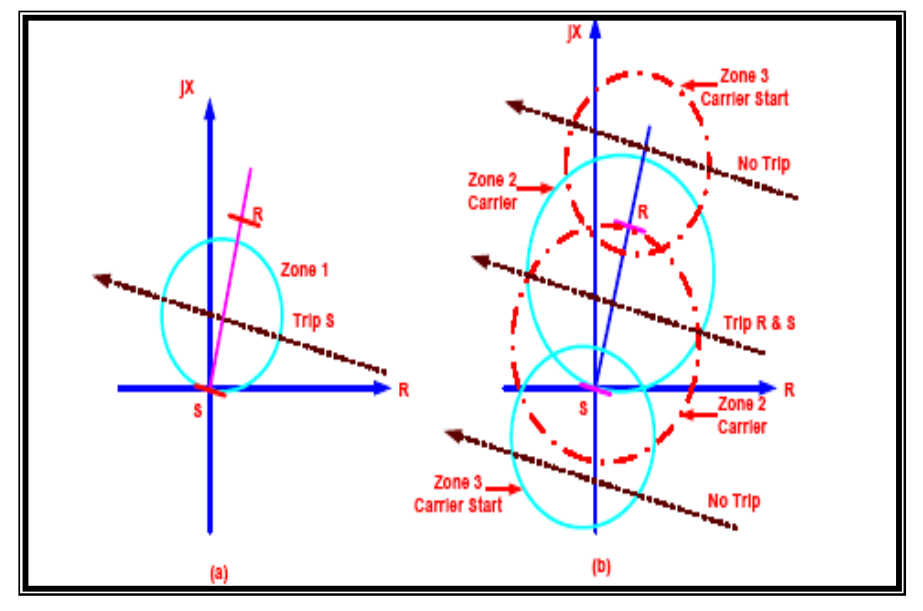

الثكل(1) خو اص الكبح الاتجاهية للقطاع الأول وحركة الممانعة عند حصول التأرجع[2]

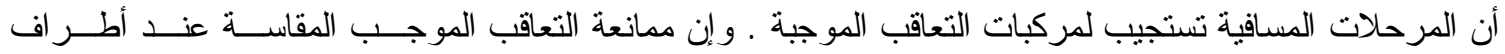

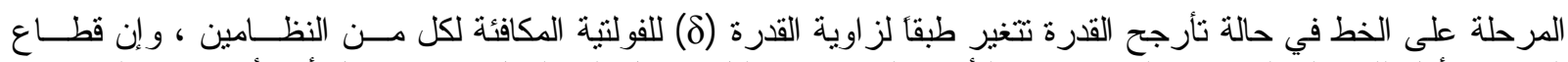

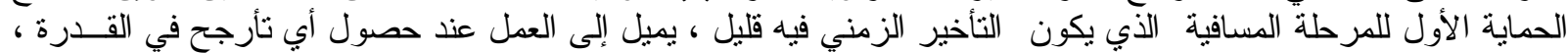

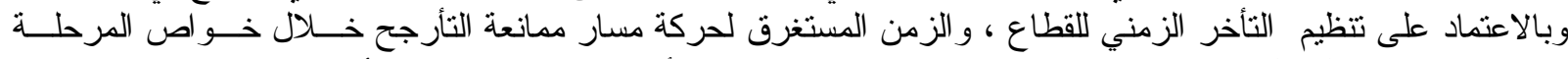

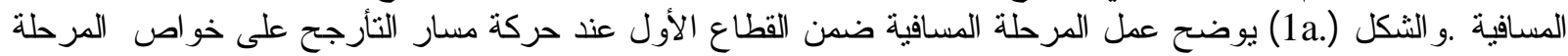
السسافية. في حين أن الثكل (1b) يوضح خو اص كبح الدقارنة الاتجاهية وكيفية تأثير ها بموقع التأرجح. 
2-2 : الممانعة المقاسة من قبل المرحلة المسافية أثناء حصول تأرجح بالقدرة [2]:

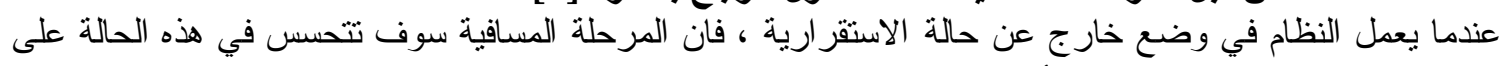

أساس أنها عطل طوري ، إذا كان مسار التأرجح يقطع خو اص المن المرحلة المسافية [2].

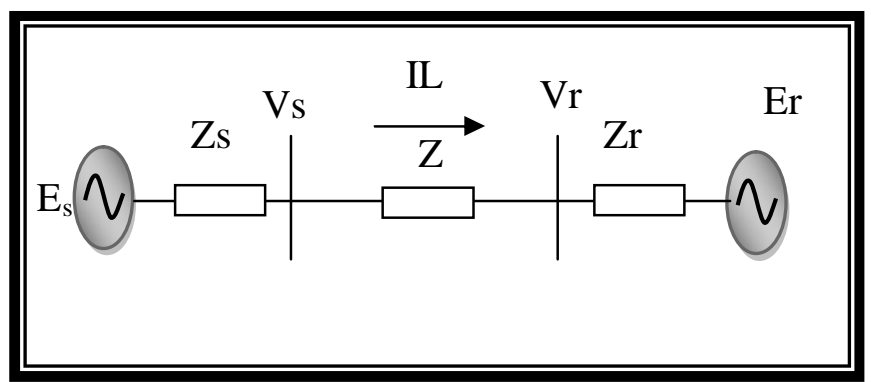

\section{الثكل (2) نظام ثنائي التغذية}

ولبرهنة هذه الحالة ، نلاحظ أن الممانعة التي تقيسها المرحلة المسافية أثناء حالة التأرجح لنظام ثنائي التغذية البـسيط

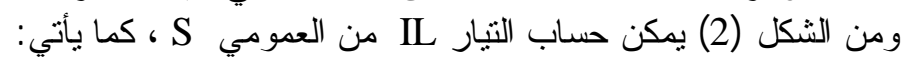
$I_{L}=\frac{E_{S}-E_{r}}{Z_{S}+Z_{L}+Z_{r}}$

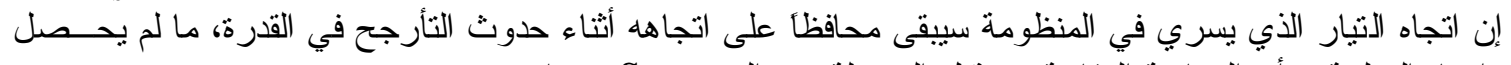
تغير في اتجاه الفولتية. وأن الممانعة المقاسة من قبل المرحلة عند العمومي S ستساوي.

$Z r e=\frac{V s}{I_{L}}=\frac{E_{S}-I_{L} Z_{S}}{I_{L}}=\frac{E_{S}}{I_{L}}-Z s=\frac{E s\left(Z_{S}+Z_{L}+Z_{r}\right)}{E s-E r}-Z s$

ولنفرض أن الفولنتة Es تتقدم على الفولتية Er بز اوية ( 8 ) وان النسبة (Es/Er ) تساوي k لذا سنحصل على الأتي: $\frac{E_{s}}{E_{S}-E_{r}}=\frac{k(\cos \delta+j \sin \delta)}{k(\cos \delta+j \sin \delta)-1}=\frac{k[(k-\cos \delta)-j \sin \delta]}{(k-\cos \delta)^{2}+\sin ^{2} \delta}$

وفي حالات خاصة عندما تتساوى القيمة المطلقة لفولتية المصدرين أي أن k يساوي واحد سنحصل على الأتي: $Z r e=\frac{V s}{I L}=\frac{(Z s+Z L+Z r)}{2}\left(1-j \cot \frac{\delta}{2}\right)-Z s$ و أخيرً فان الممانعة المقاسة من قبل المرحلة المسافية ستكون كالأتي :

$\frac{E s}{E s-E r}=\frac{1}{2}\left(1-j \cot \frac{\delta}{2}\right)$

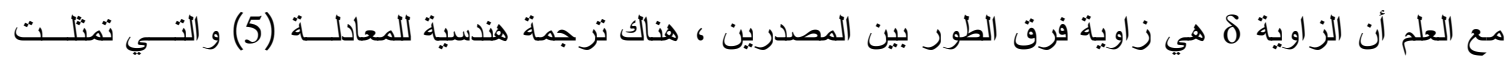

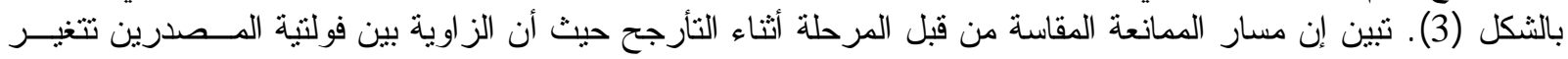

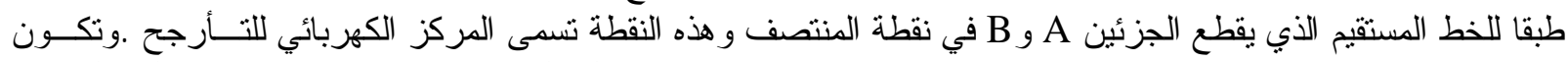

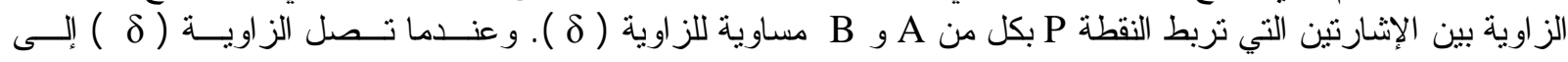

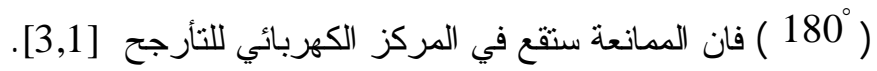




\section{$\begin{array}{llll}\text { Al-Rafidain Engineering } & \text { Vol.17 } & \text { No.5 } & \text { October } 2009\end{array}$}

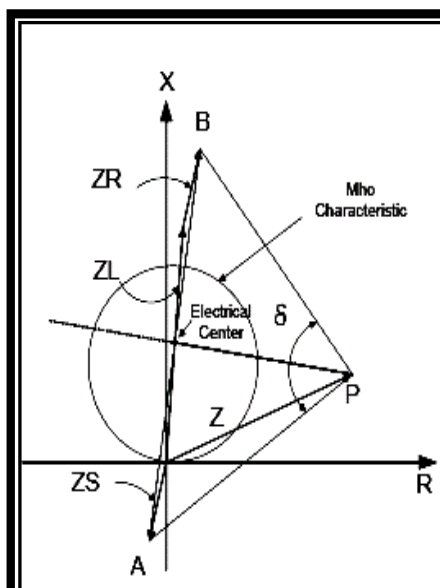

(a)

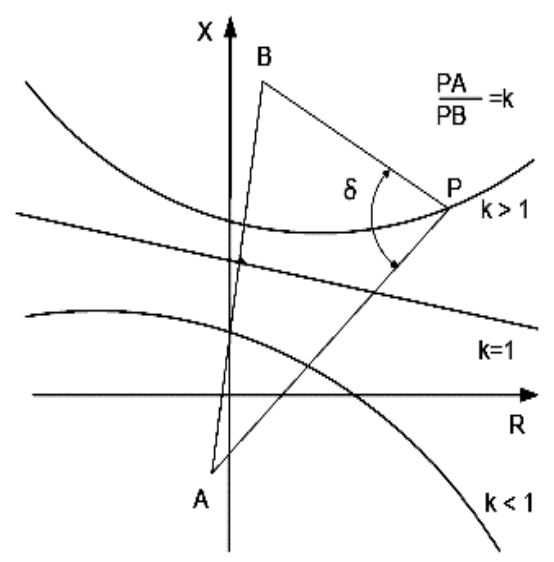

(b)

الشكل (3) مسار المماتعة عند حصول حالة التارجح [1]

3-2

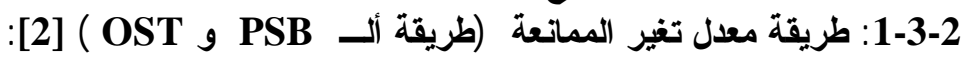

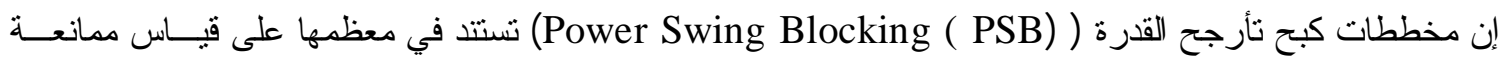

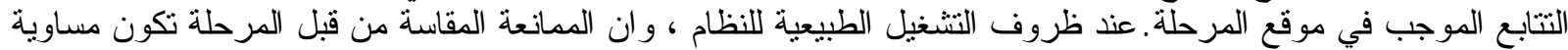

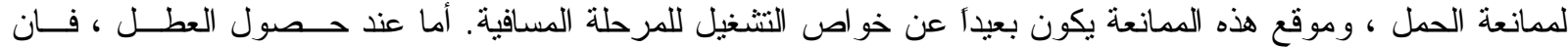

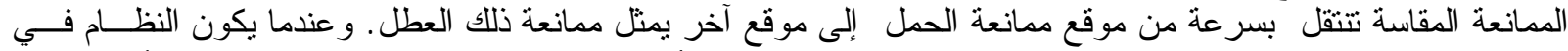

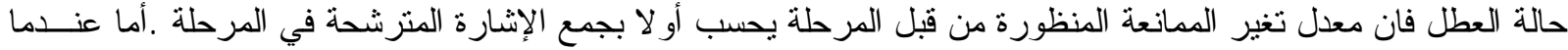

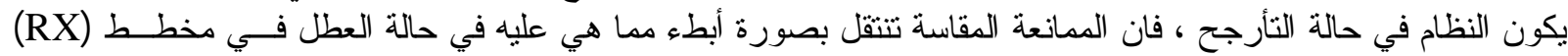

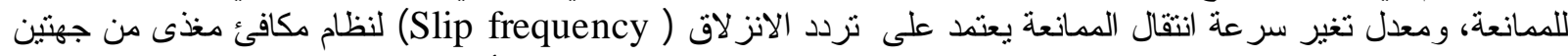

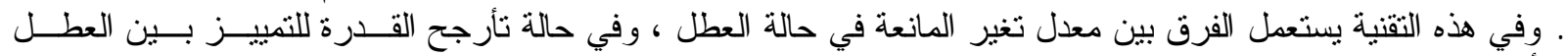

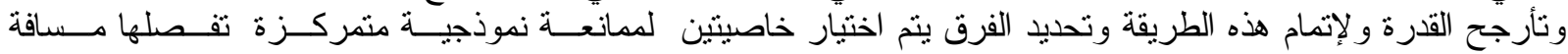

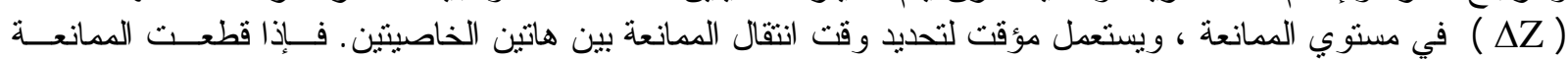

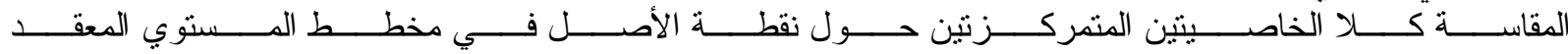
(Complex Plane )

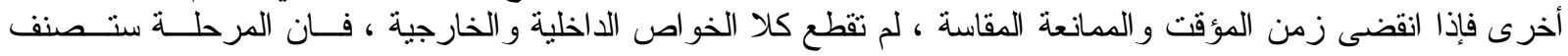

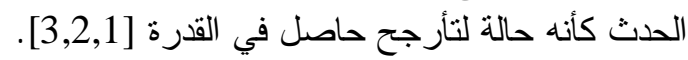

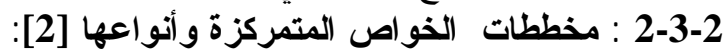

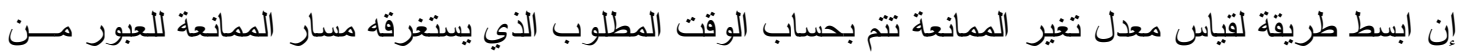

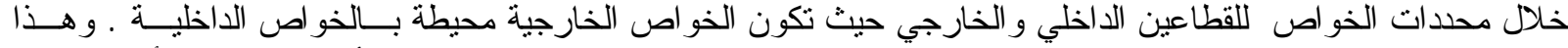

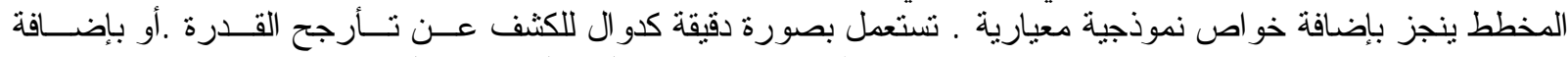

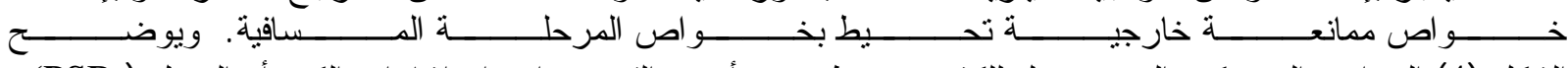
الثكل (4) الخو اص المتمركزة التي تستعمل للكثف عن ظروف تأرجح القدرة و إصدار إنشار ات الكبح أو الفصل ( PSB)

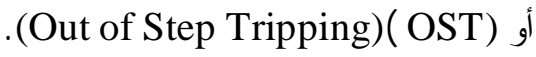

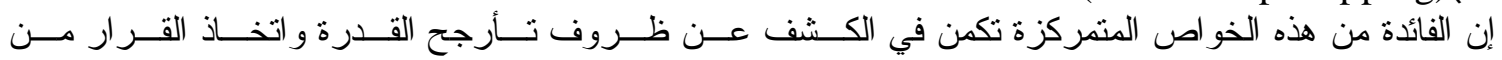

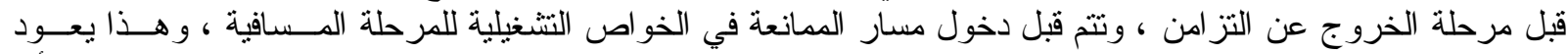

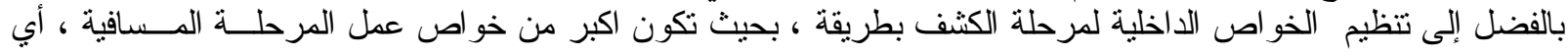


بمعنى أن تكون اكبر من خو اص التتغيل لآخر قطاع محمي.ويكون التتظيم الرئيسي للمرحلة محدداً بتتظيم الحدود الخارجية

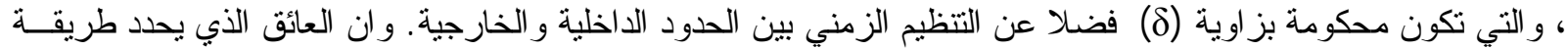

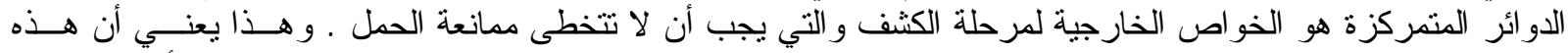

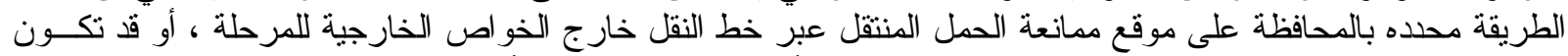

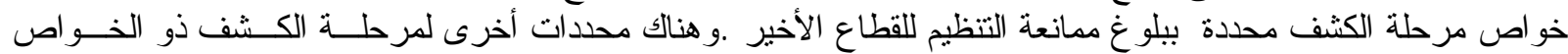

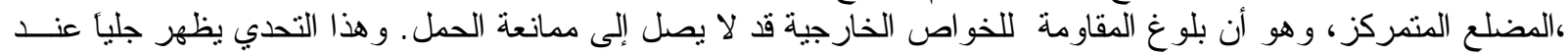

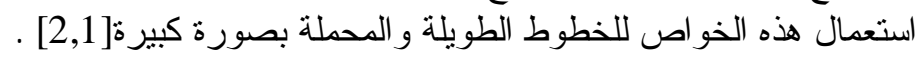

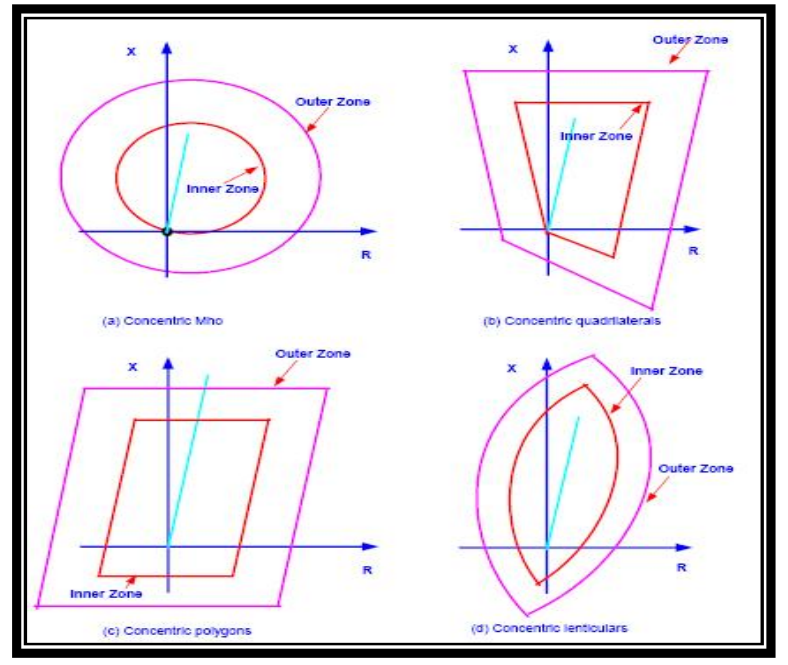

الثكل (4) خواص ألـ (PSB و (OST) المتمركزة للحماية المسافية [2]

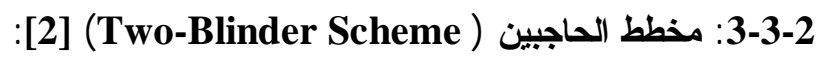

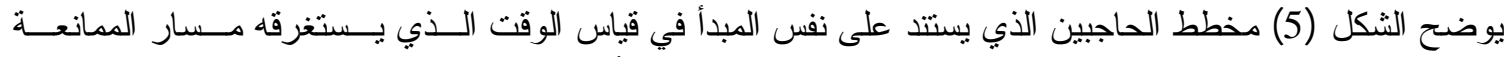

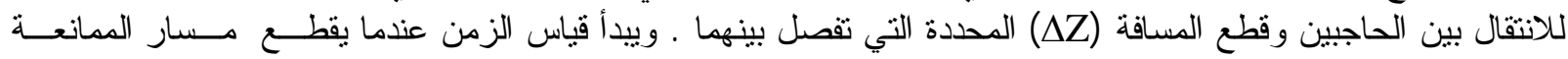

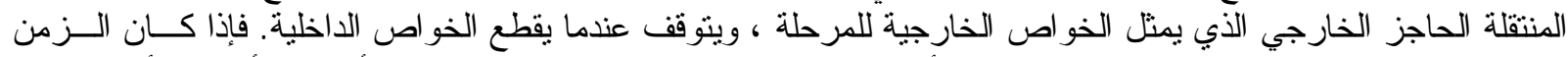

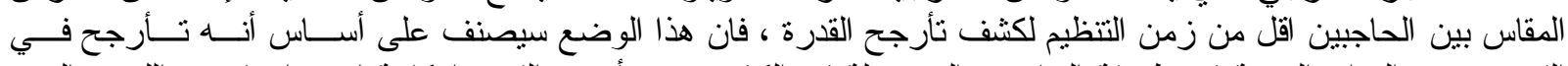

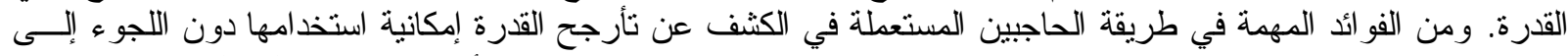

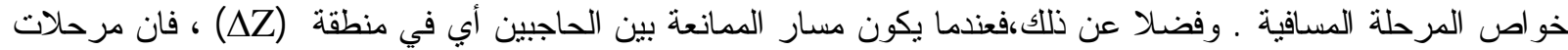

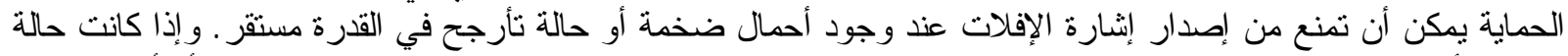

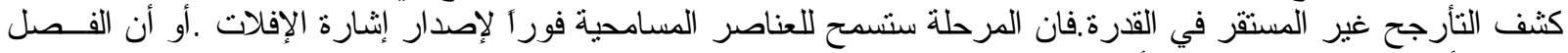

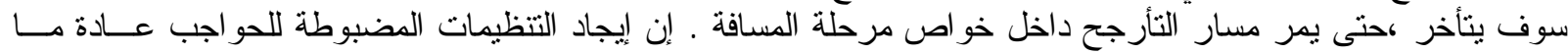

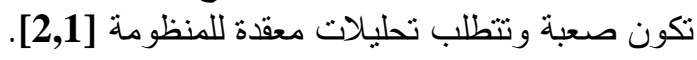

\section{3: آلية تمثيل ونمذجة خواص مرحلة مركلة الخروج عن التزامن وعملها مع مرحلة المسافة:

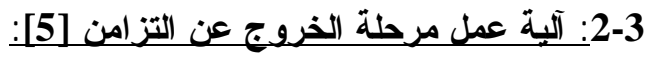

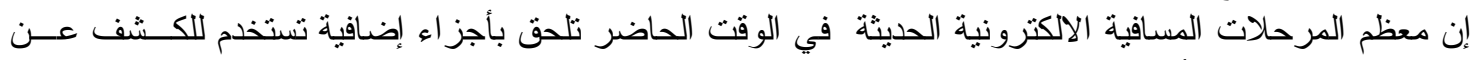

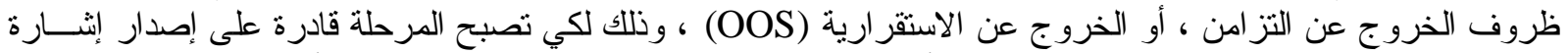

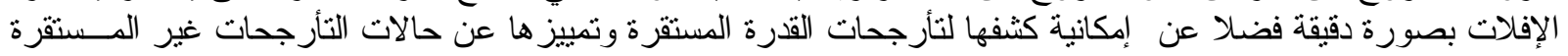

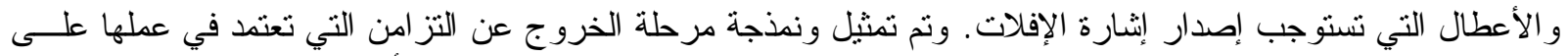

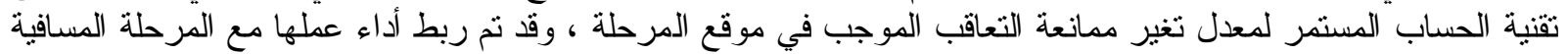

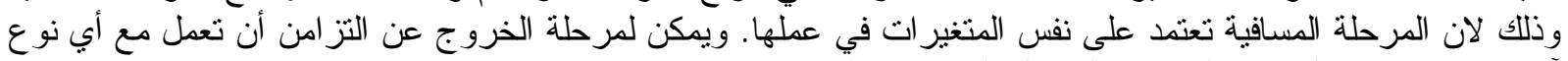
آخر من مرحلات الحماية وليس مع المرحلة المسافية فقط. 


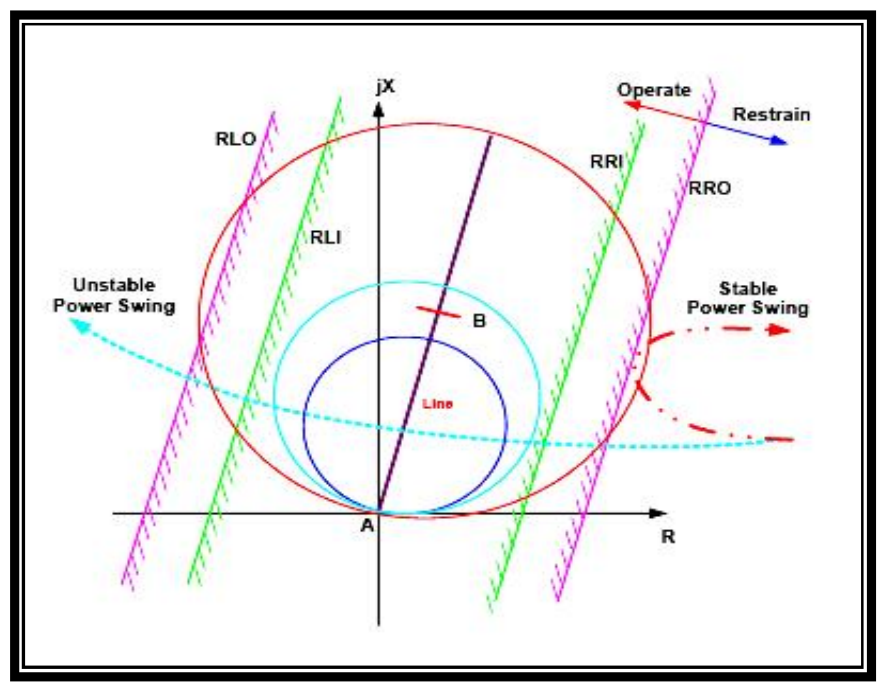

الثكل (5) مشروع الحاجبين لمرطلة الخروج عن التزامن [2]

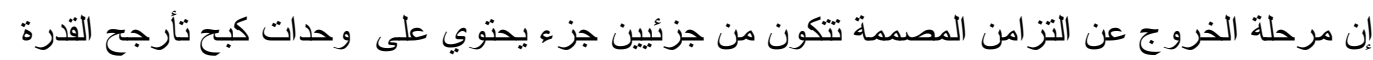
التئ Out-Of-Step Blocking (OSB)

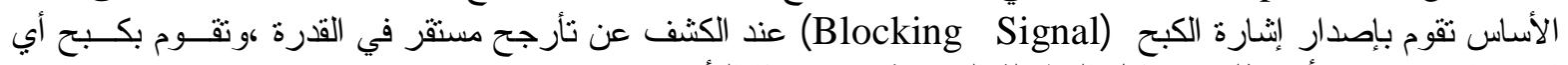
إثنارة إفلات يمكن أن تطلق من قبل المرّحلة المساقية بسبب هذا الثأرجح .

أما الجزء الثاني فيحتوي على وحدات الفصل (OST) وفي هذا الجز ء ينت تثتخيص حالات تــأرجح القـدرة

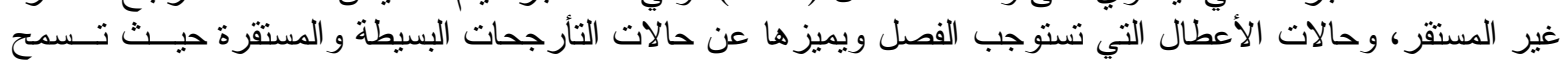

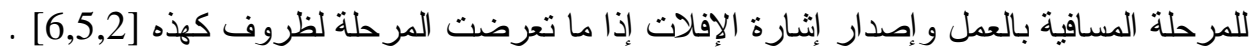

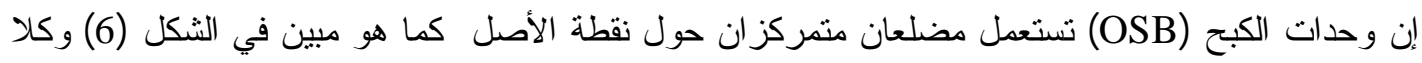

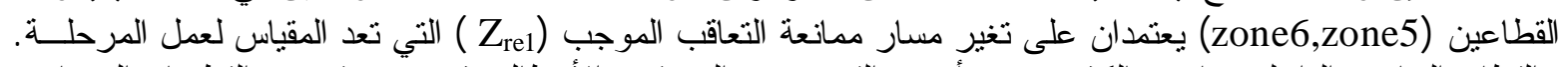

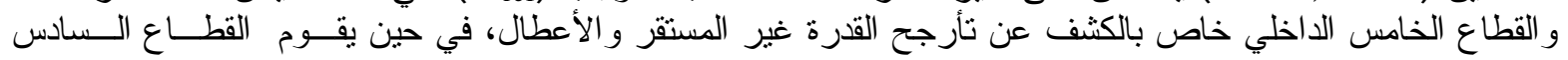

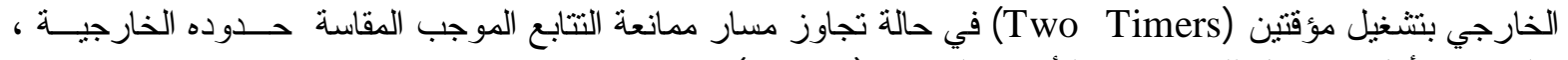

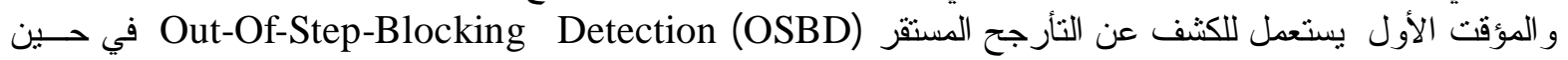

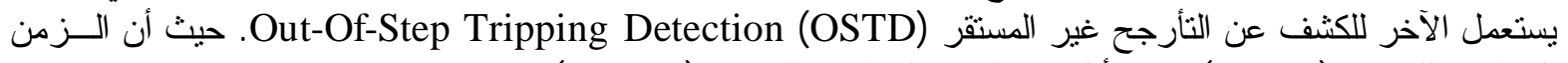

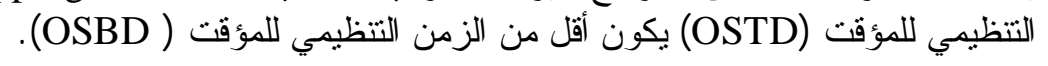

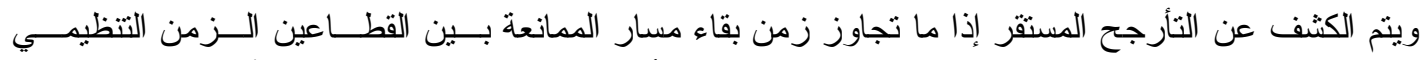

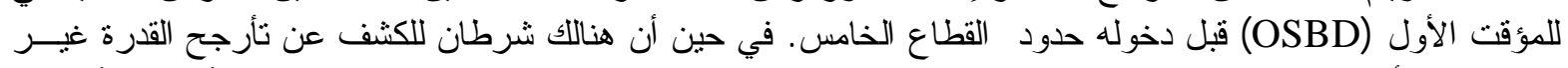

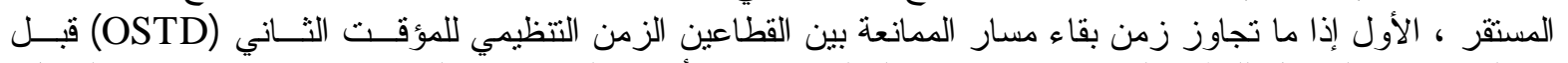

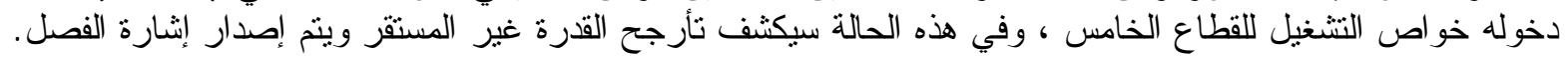

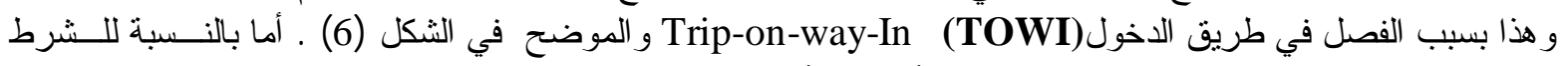

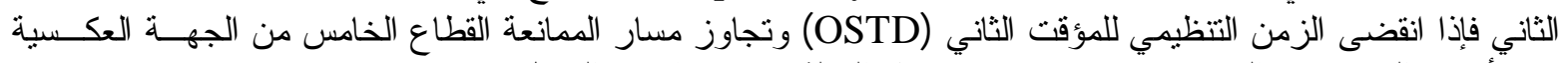

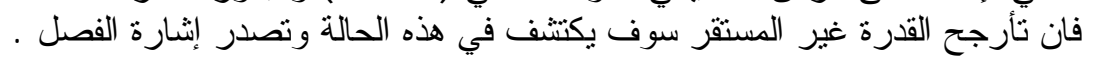

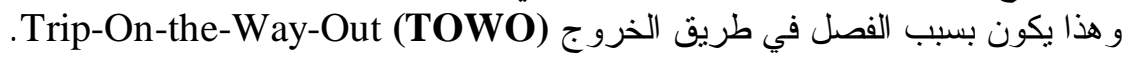




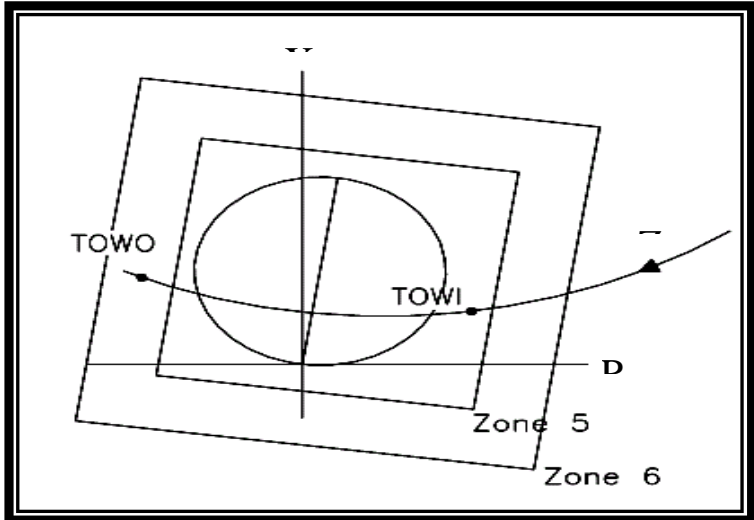

الشكل ( 6 ) : خو اص مرحلة الكشف عن تأرجح القدرة (OSBD)

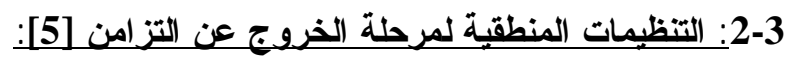

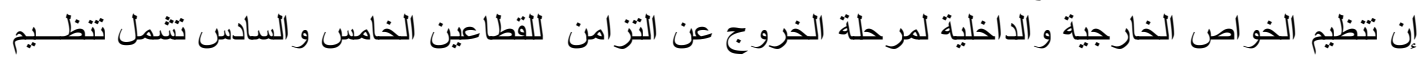

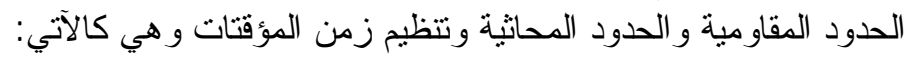

1-2-3: تنظيم الحدود المقاومية ( Resistive Blinder Setting):

إن الحدود المقاومية ( R1R5,R1L5,R1R6,R1L6 ) هي حدود الخواص الداخلية و الخارجية لمرحلة الخروج

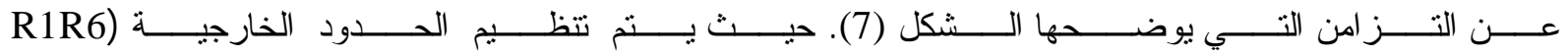
و R1L6 اعتمادأ على أعظم حمل منتقل في المنظومة في كلا الاتجاهين الأمامي و العكسي أما الحدود المقاومية الداخلية

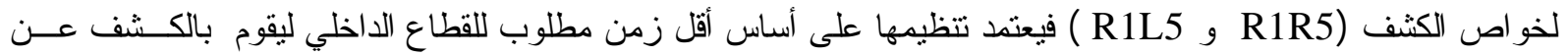
تأرجح القدرة المستقر (6,5BD) (OSB).

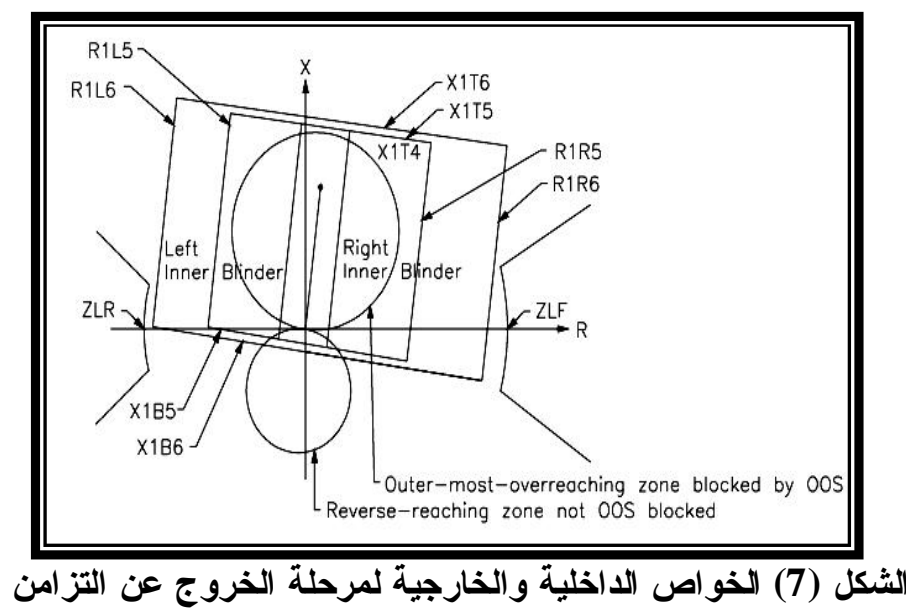

وفي الغالب يتم تتظيم الحد الخارجي ( R1R6 ) على نحو, اقل من ممانعة أعظم حمل في الاتجاه الأمامي ، وكــــللك

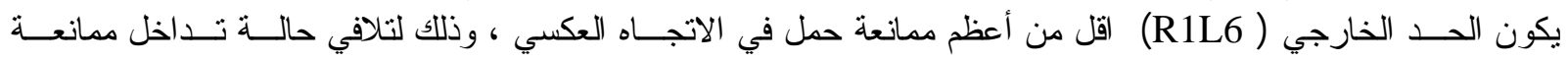

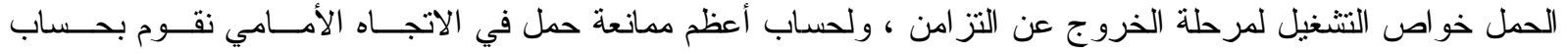

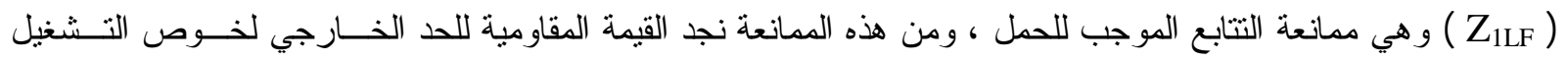

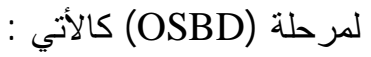

$Z_{1 L F}=\frac{V^{2}}{S_{1 F \operatorname{MAX}}}$ 


$$
R 1 R 6 \leq \frac{Z_{1 L F}}{C_{1}}
$$

أما لحساب أعظم ممانعة حمل في الاتجاه العكسي فإنتا نوجد الممانعة Z1LR و التي تساوي أعظم ممانعة حمل

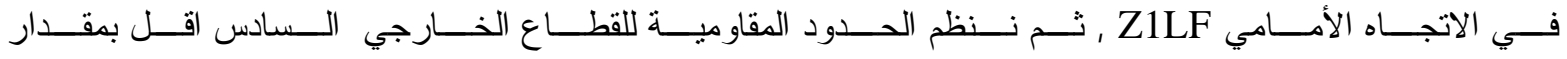

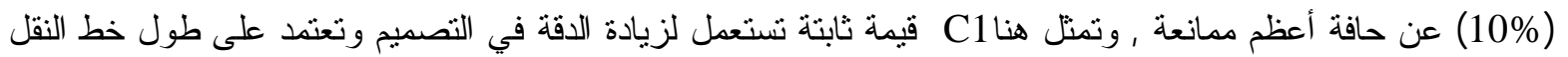

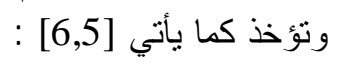
: للخطوط الأطول من : 100 ميل : $C_{1}=1.1$ : ل لخطوط بطول بين $\mathrm{C}_{1}=1.2$

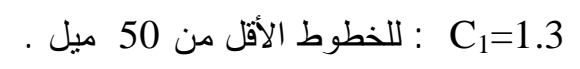

و لإتمام التصميم نفرض قيمة (OSBD) وهي قيمة تنظيمية تقاس بعدد الدورات التي يفترض أن يكثف التأرجح خلالها ، كذلك نفرض أعظم تردد للانز لاق (

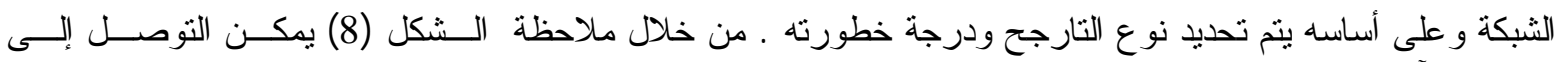

$$
\begin{aligned}
& \frac{\text { AngR } 5-\text { AngR6 }}{O S B D}\left(\frac{\operatorname{deg} r e e}{\text { cycle }}\right)=\frac{360(\mathrm{deg} . / \text { cycle }) \cdot f_{\text {slip }}(\text { cycle } / \mathrm{sec})}{f_{s}(\text { cycle } / \mathrm{sec})} \\
& \text { AngR } 5=\frac{360(\mathrm{deg} / \text { cycle }) . f_{\text {slip }}(\text { cycle } \mathrm{sec}) O S B D}{f_{s}(\text { cycle } \mathrm{sec})}+\text { AngR6 } \\
& \text { AngL5 }=\frac{360(\mathrm{deg} . / \text { cycle }) \cdot f_{\text {slip }}(\text { cycle } / \mathrm{sec}) \cdot O S B D}{f_{s}(\text { cycle } / \mathrm{sec})}+\text { AngL6 } \\
& \operatorname{AngR6}=2 \cdot \operatorname{ATAN}\left(\frac{Z_{s 1}+Z_{L 1}+Z_{r 1}}{2 . R 1 R 6}\right) \\
& \operatorname{AngL6}=2 . \operatorname{ATAN}\left(\frac{Z_{s 1}+Z_{L 1}+Z_{r 1}}{2 . R 1 R 6}\right)
\end{aligned}
$$

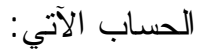

حيث إن $f_{s}$ : هو التردد الاعتيادي (المقنن) لنظام القدرة إما 50 أو 60 هيرنز.

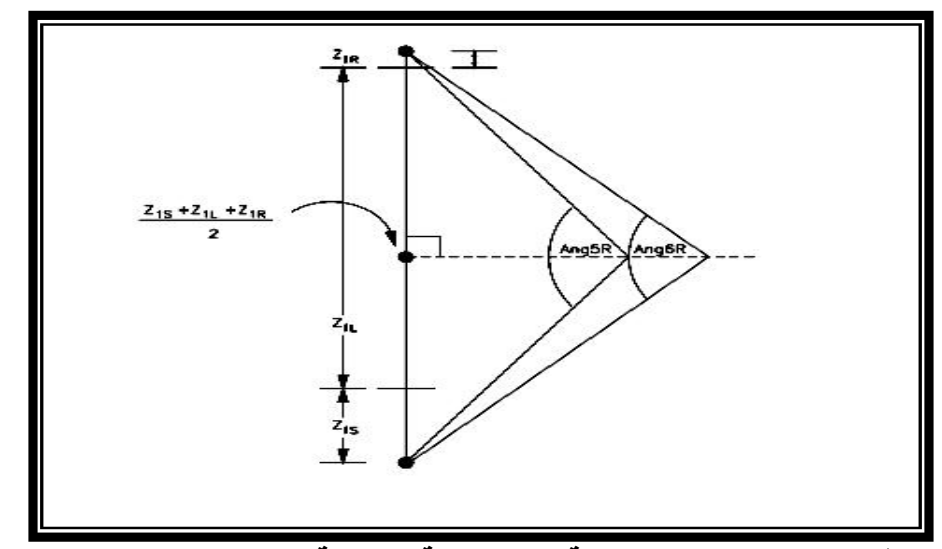

الثكل (8) تنظيم زوايا الحدود الداخلية والخارجية لمرحلة الخروج عن التز امن[5] 
$R 1 R 5=\frac{Z_{s 1}+Z_{L 1}+Z_{r 1}}{2 \cdot \operatorname{TAN}(\operatorname{AngR} 5 / 2)}$ أما لحساب الحدود المقاومية للقطاع الخامس فتكون كالآتي:

$R 1 L 5=\frac{Z_{s 1}+Z_{L 1}+Z_{r 1}}{2 \cdot T A N(A n g R 5 / 2)}$

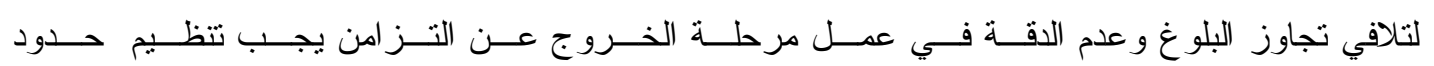

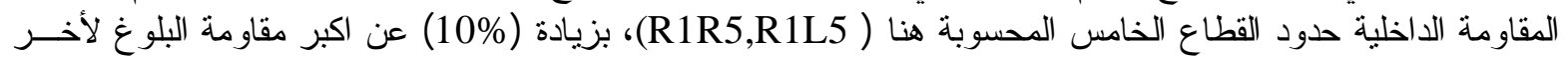

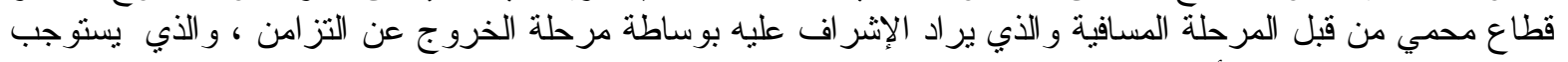

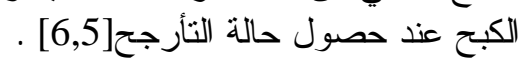

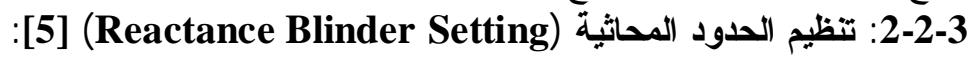

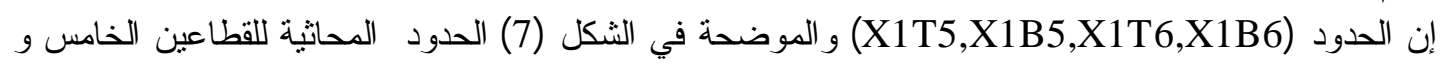

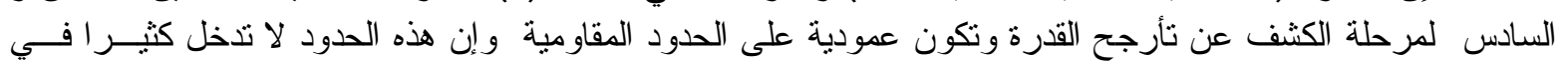

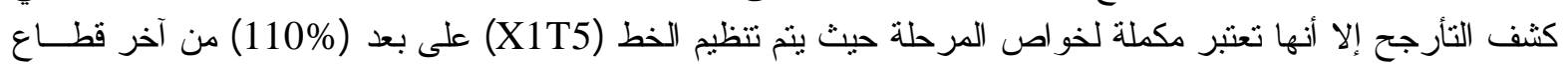

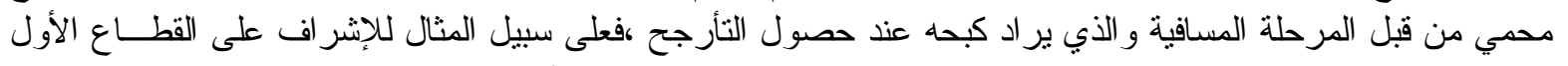

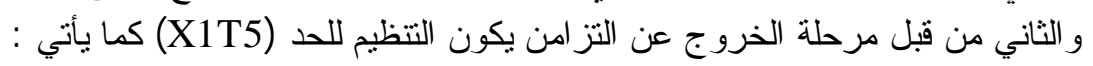

$\mathrm{X} 1 \mathrm{~T} 5=110 \% 120 \% * \mathrm{Z}_{\mathrm{L} 1} *\left(\mathrm{CT}_{\text {ratio }} / \mathrm{VT}_{\text {ratio }}\right)$

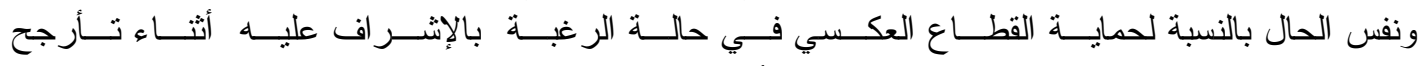

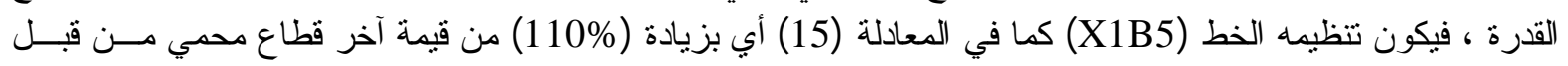
المرحلة المسافية.

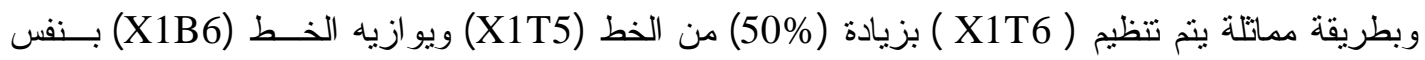

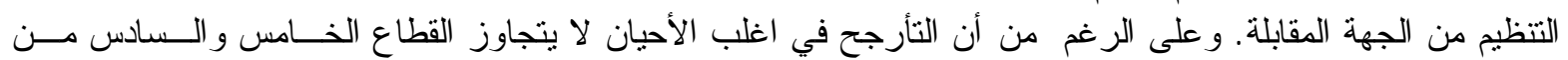

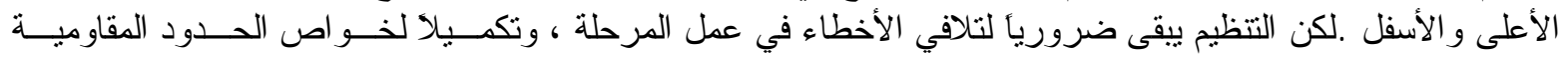

3-2-3: تنظيم المؤقت [5]:

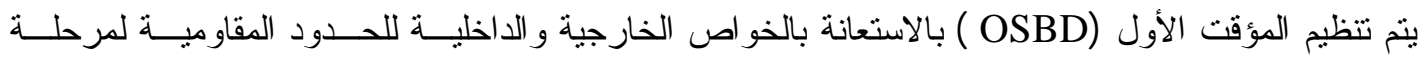
الخروج عن التز امن وذللك طبقا للعلاقة الآتية : $O S B D=\frac{(\text { Ang } 5 R-\text { Ang } 6 R) \cdot f_{s}(H z)}{360^{\circ} / \text { cycle. } f_{\text {slip }}(H z)}$

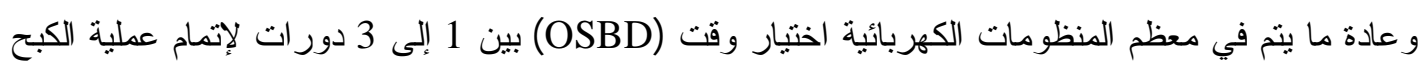

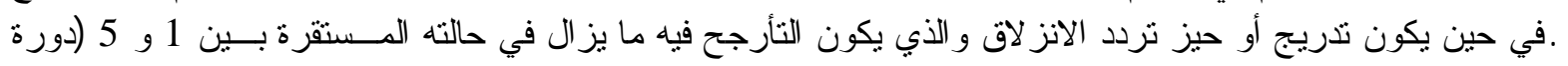
الثانية)

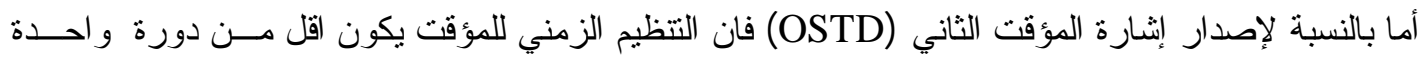

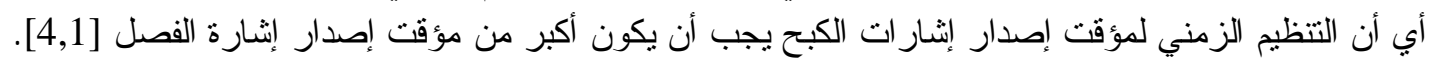

3-3: نمذجة وتمثيل المرّطة المسافية من نوع المسامحية:

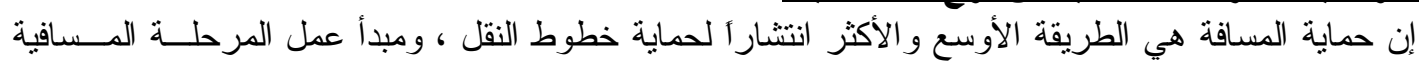

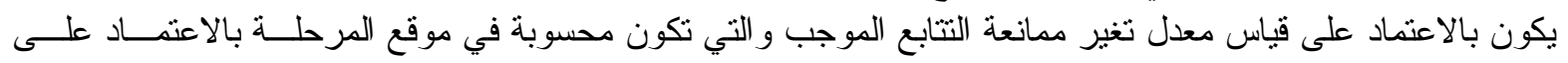

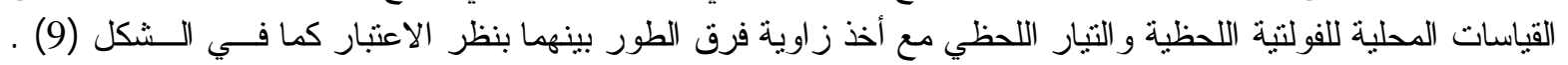
حيث تستجيب المرحلة إلى الممانعة بين موقع المرحلة وموقع العطل ، و التي تنتاسب مثاليأ مع المسافة بين موقع المرحلة ونقطة العطل. 
إن مرحلات الكسافة تستخدم للقيام بالو اجبات الآتية:

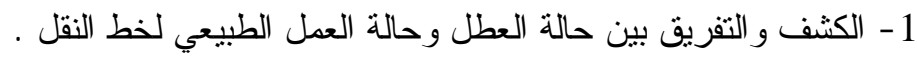

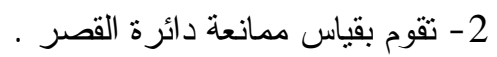

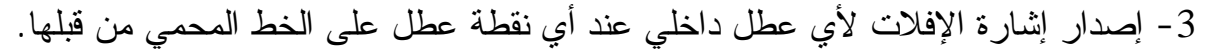

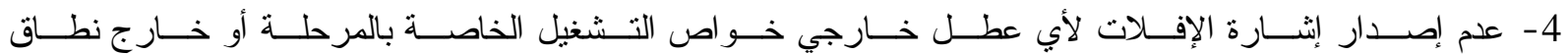

العمل [7].

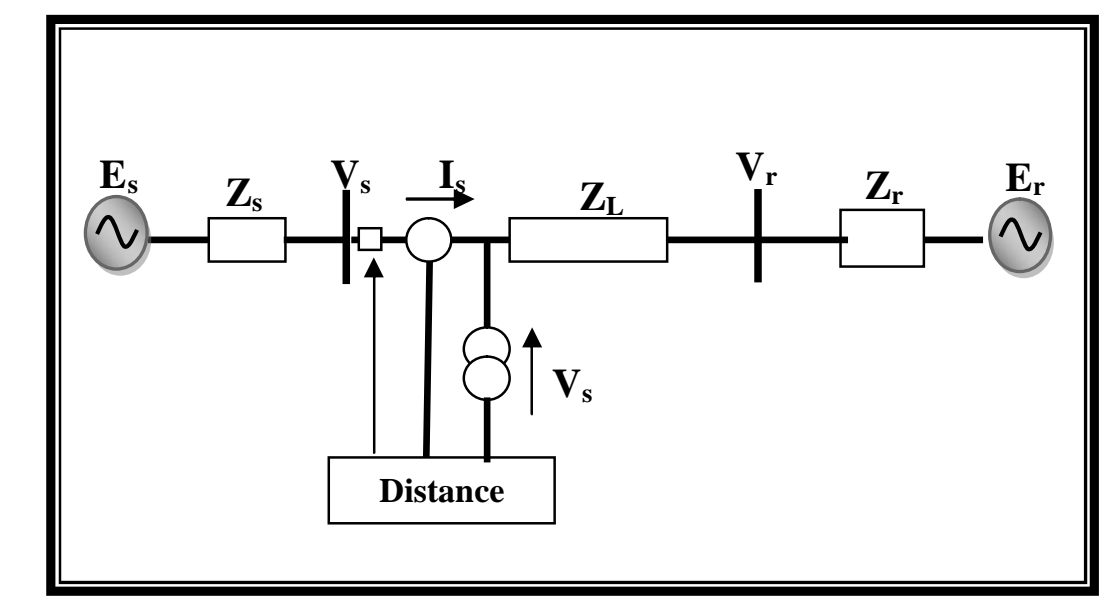

الثكل (9) يوضح موقع المرحة المسافية عذ العمومي القريب من جهة الإرسال

4-3: تمثيل المرحلتين بو اسطة الحاسبة:

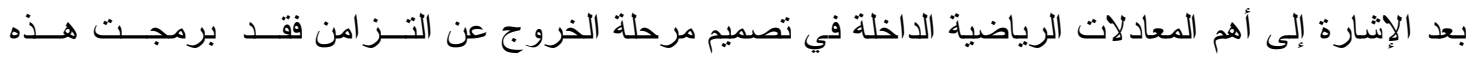

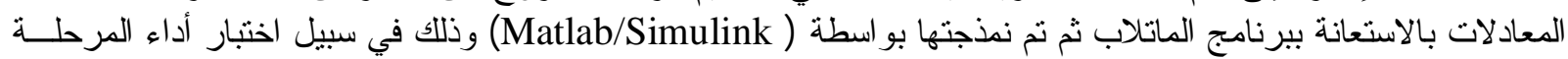

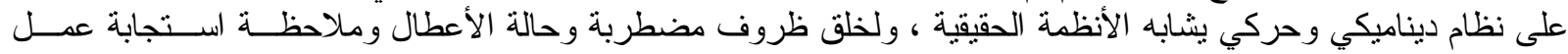

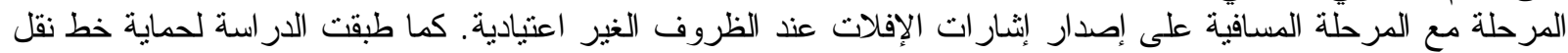

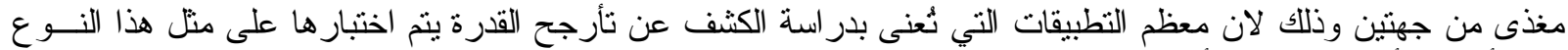

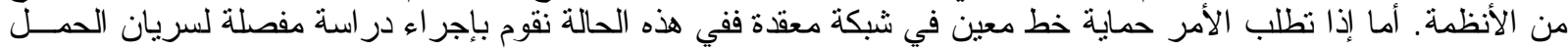

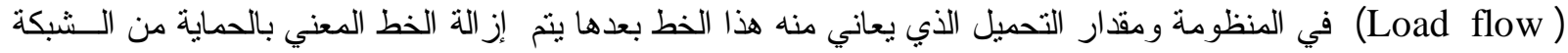

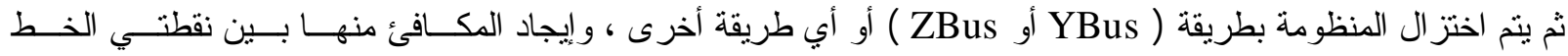

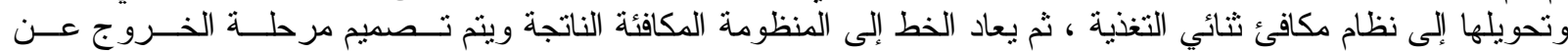

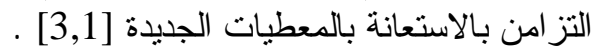
1-4-3 1-3 تمثيل مرحلة الخروج عن التزامن:

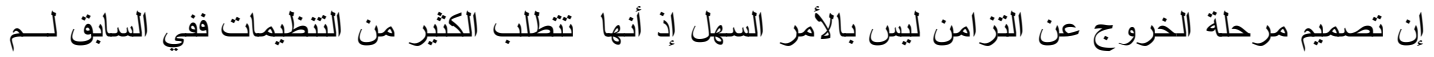

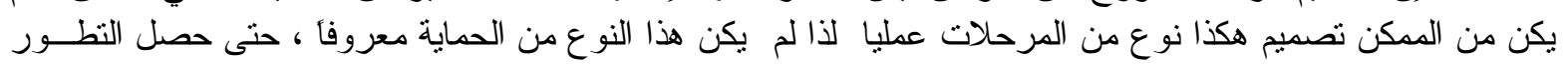

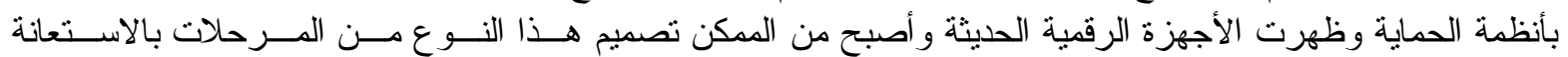

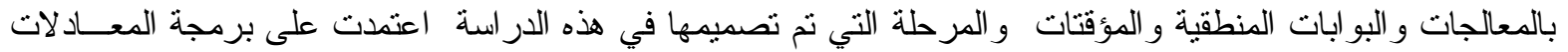

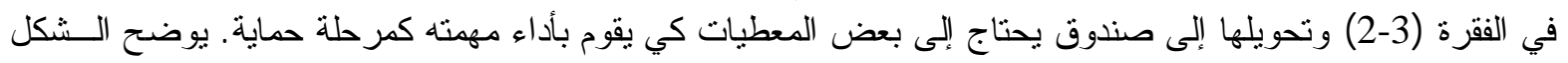
(10) التركيب الداخلي لمرحلة الخروج عن الثزامن. 


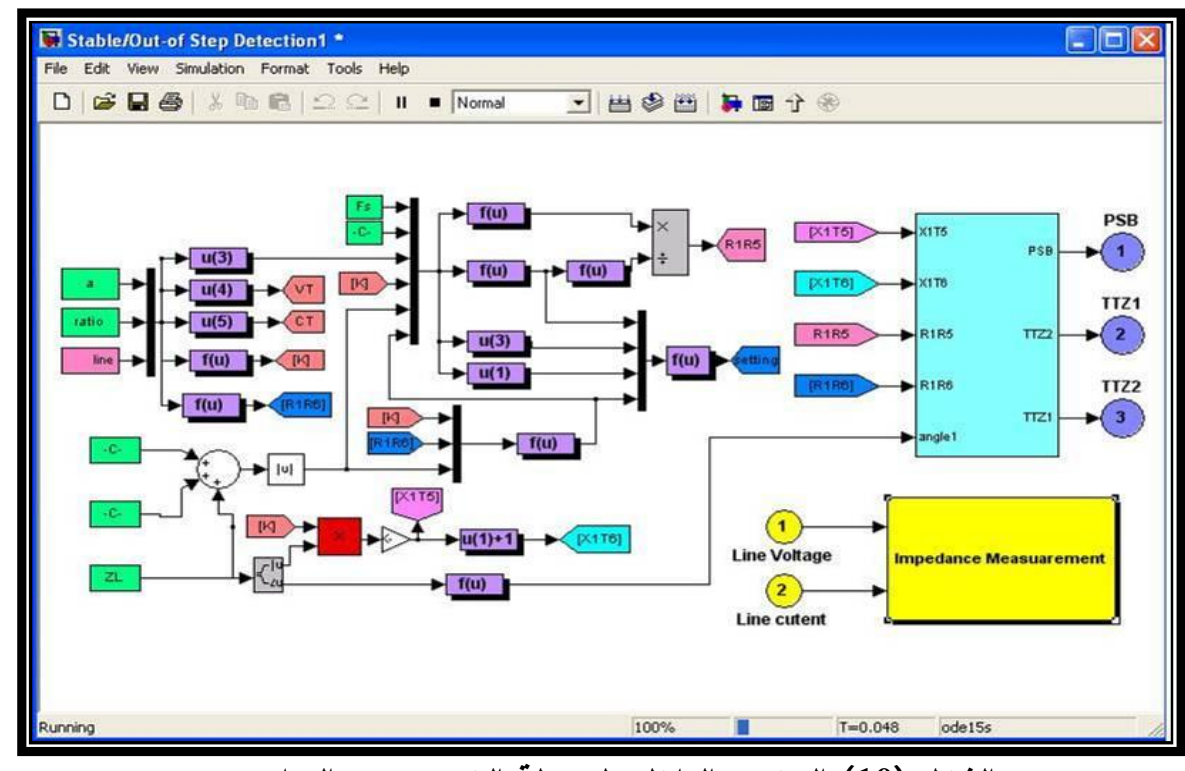

الثكل (10) التركيب الأخلي لمرحلة الخروج عن التزامن

: 2-4-3 : تمثيل مرحلة المسافة

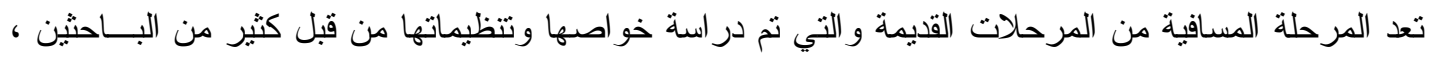

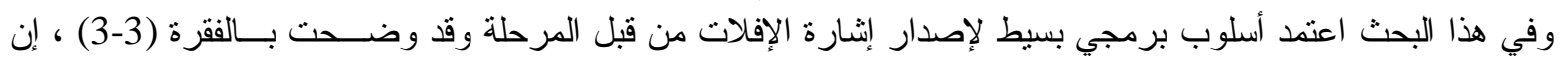

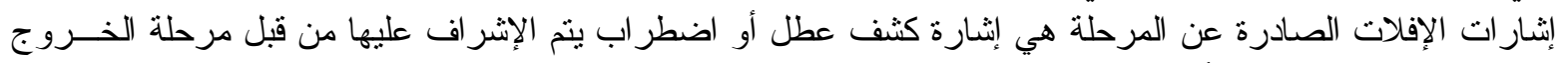

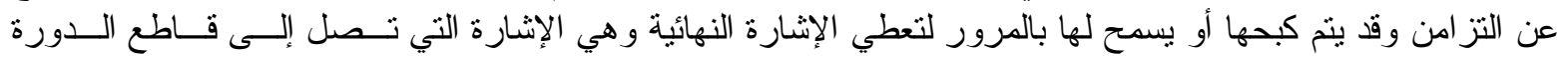
ويوضح الثكل (11) التزكيب الداخلي لمرحلة المسافية.

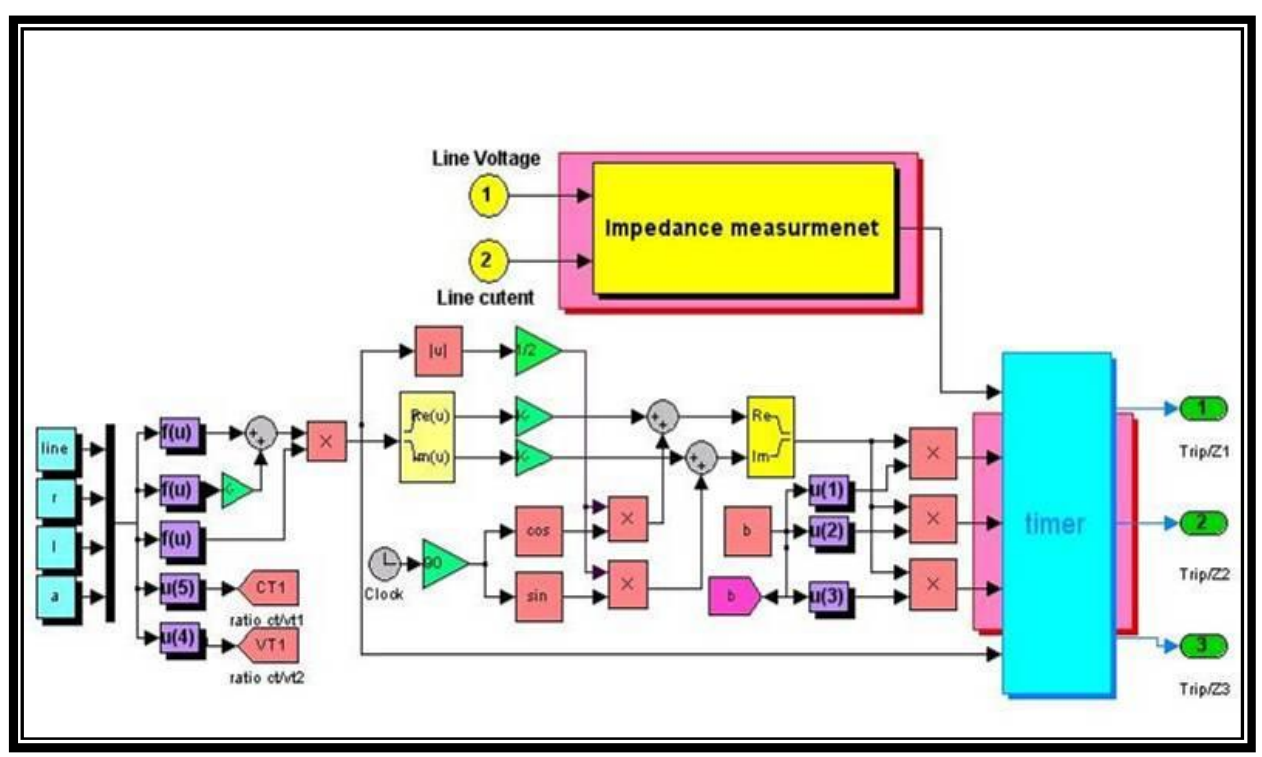

الشكل (11) يوضح التركيب الداخلي للمرحلة المسافية المصممة بواسطة برنامج الماتلاب 


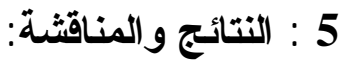

1-5: المنظومة في حالة التشغيل المستقر بوجود الأعطال:

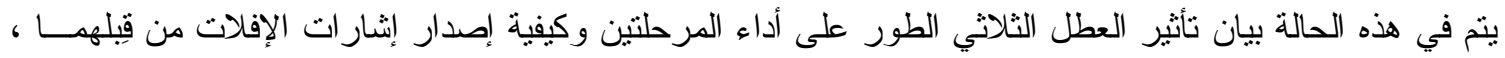

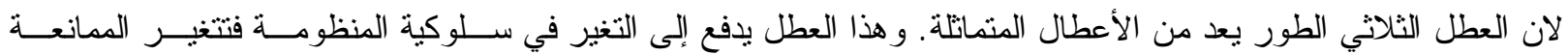

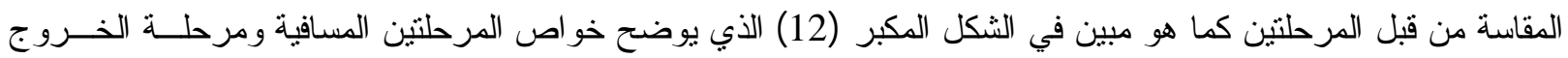

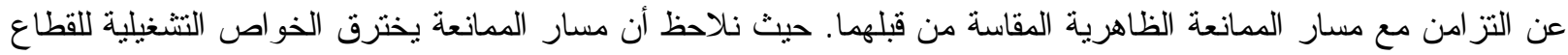

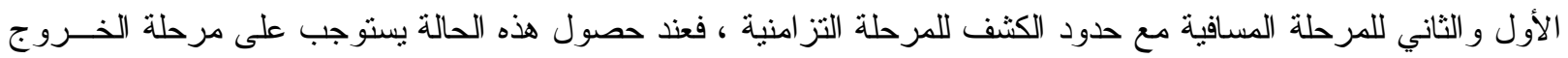

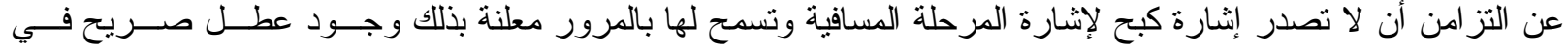

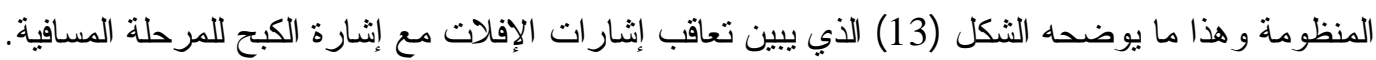

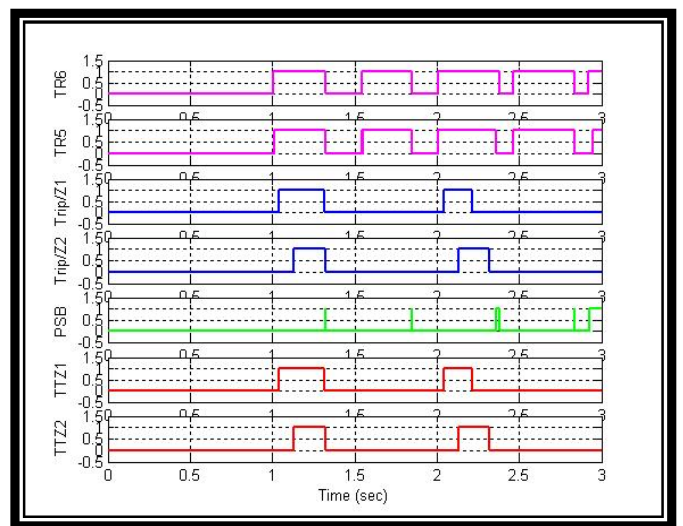

الثكل (13) تعاقب إثشارات الإفلات للمرحلتين مع إثارة الكبح للمرحلة المسافية

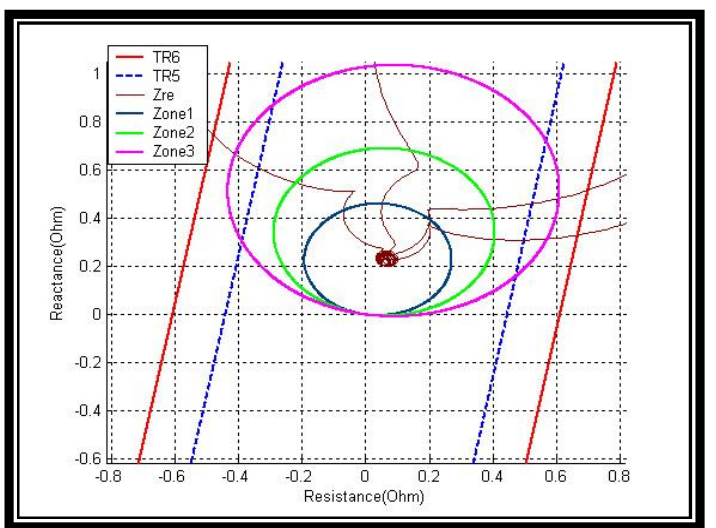

الثنكل (12) خواص المرحلتين مع مسار الممانعة الظاهرية المقاسة من قبلهما للحالة المستقرة بوجود عطل ثلاثي الطور

2-5: المنظومة في حالة التأرجح دون وجود العطل ( الحالة المستقرة ) :

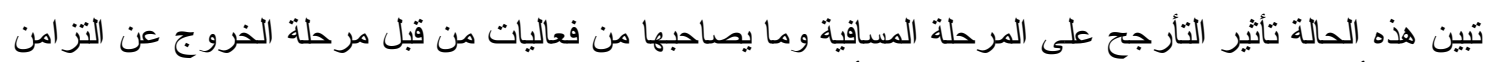

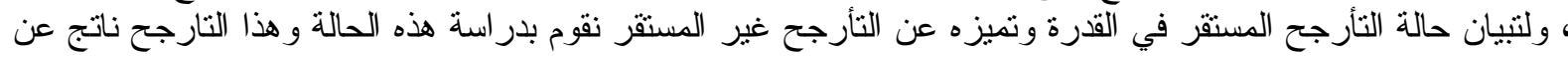

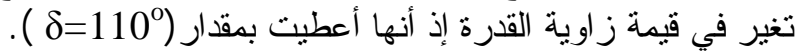

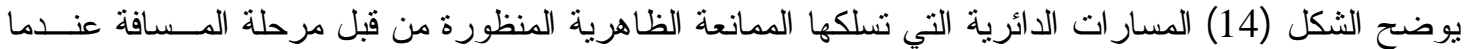

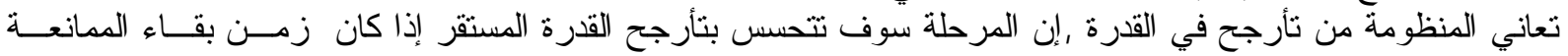

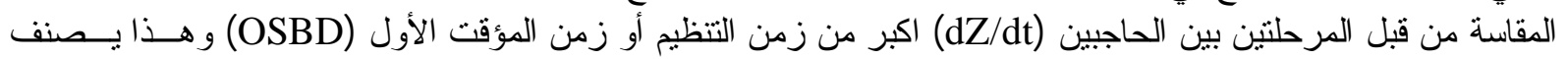

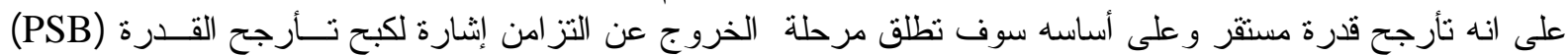

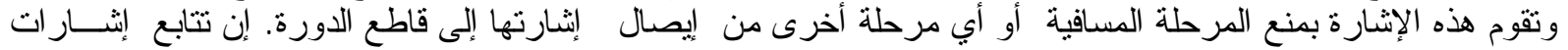

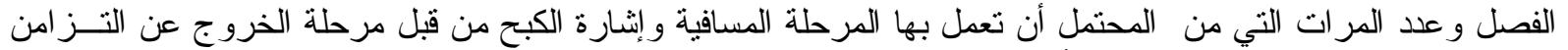

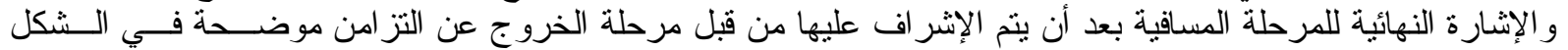

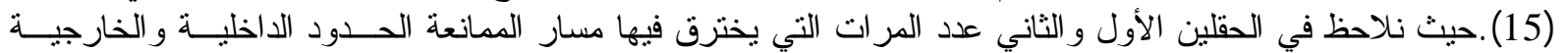

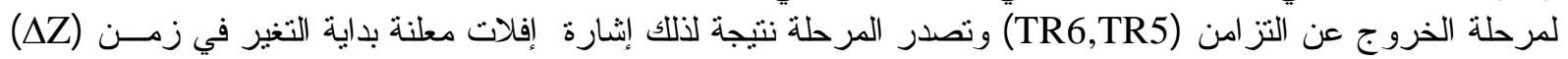

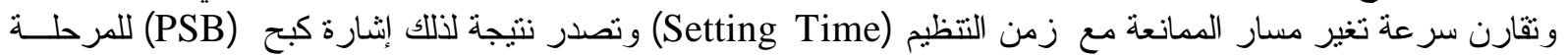

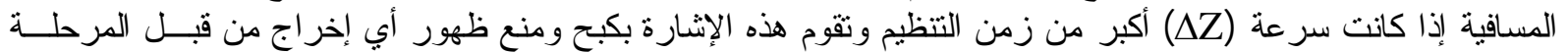

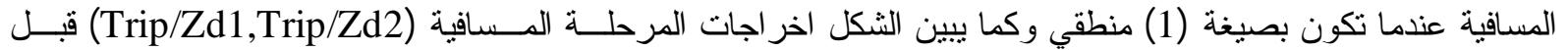

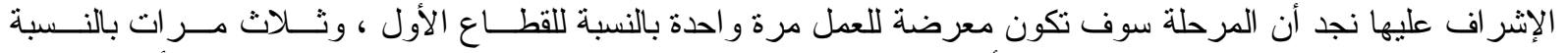

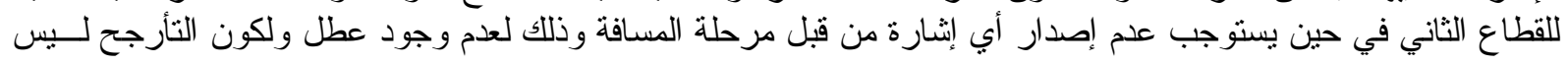




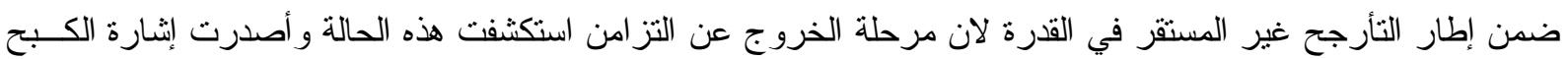

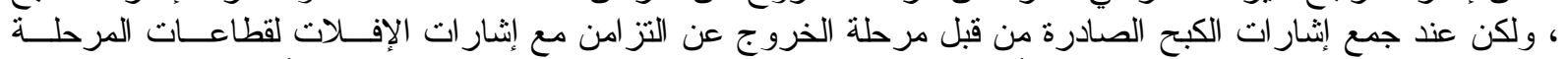

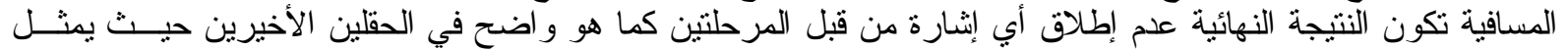

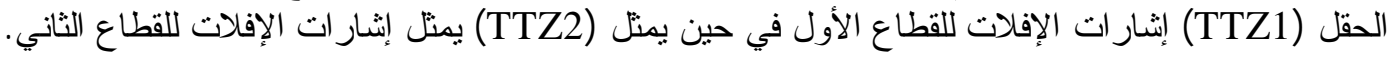

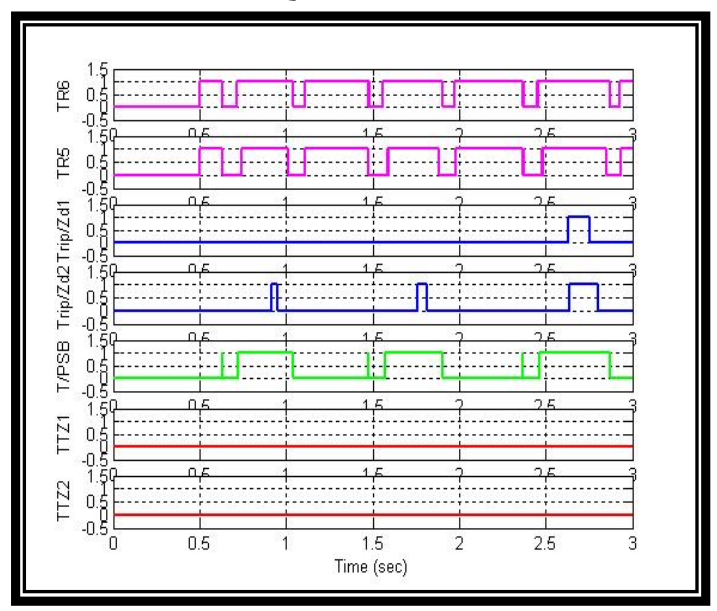

الثكل (15) إثارات الإفلات من قبل المرحتين مع إثنارة

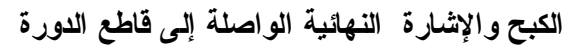

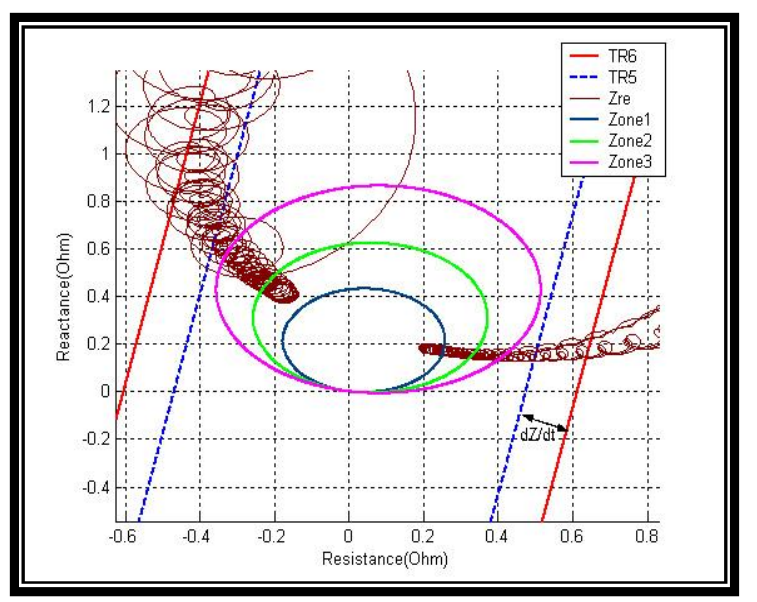

الثكل (14) مسار ات الممانعة مع خو اص المرحلتين

1-2-5

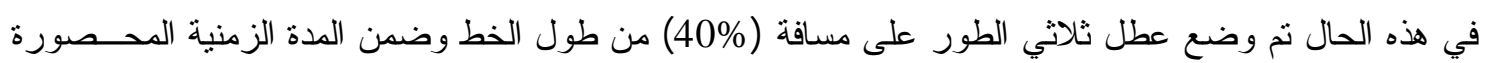

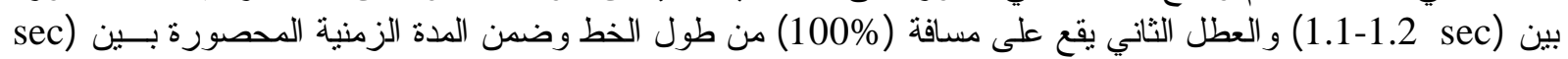

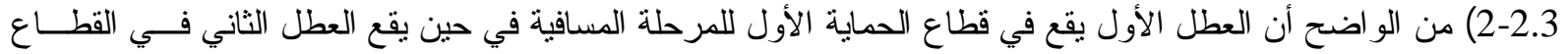

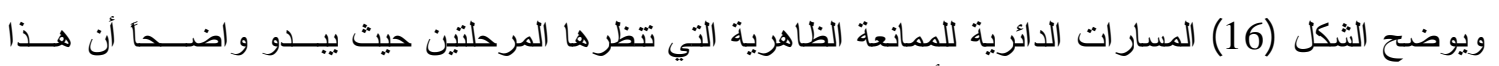
الثاني.

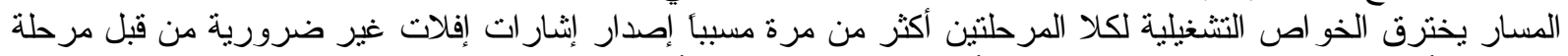

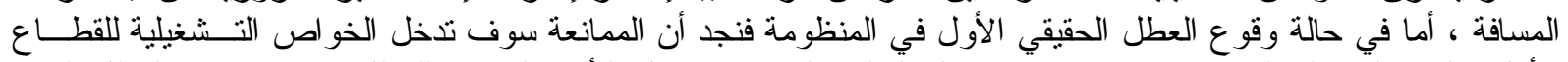

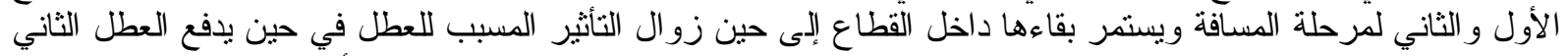

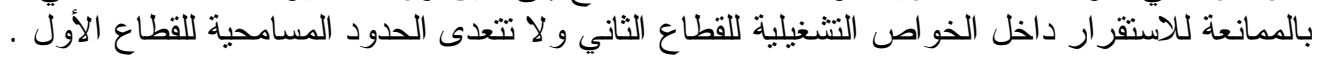

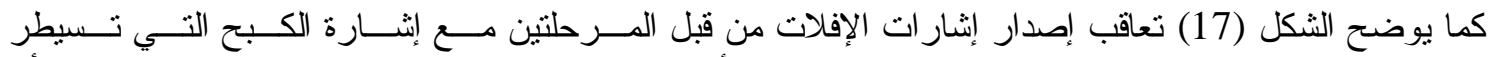

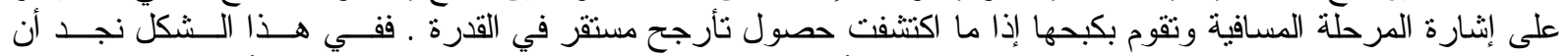

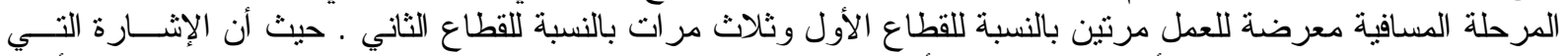

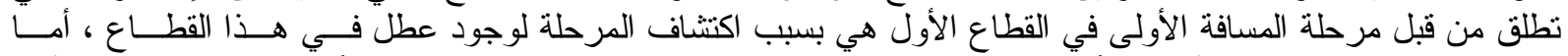

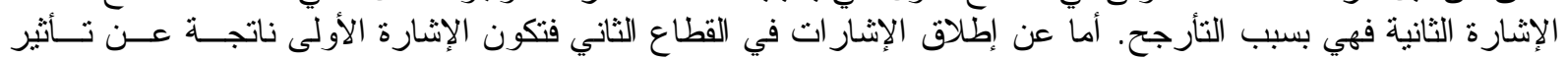

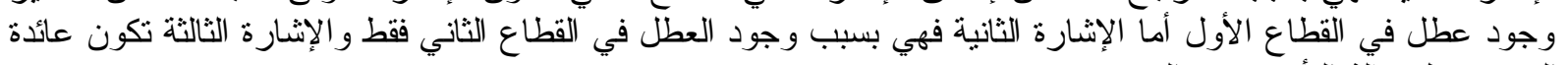

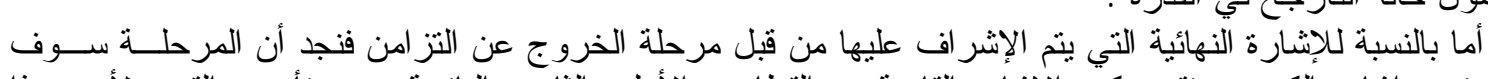

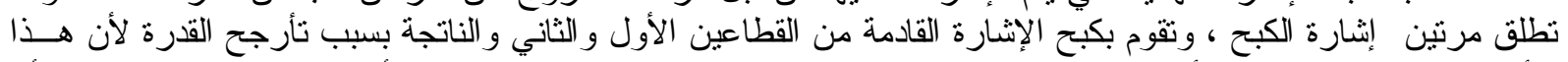

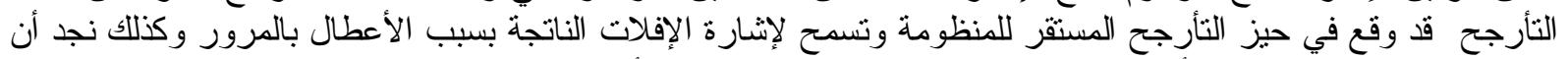

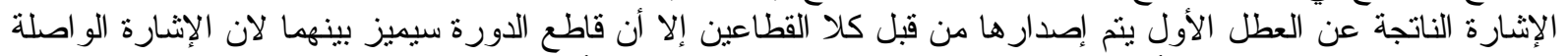

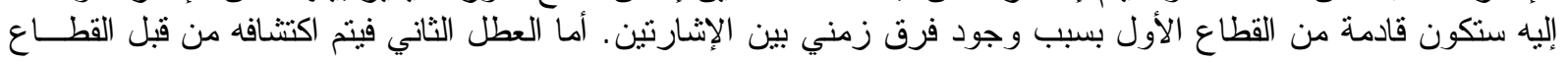

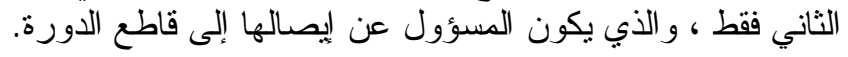




\section{Al-Rafidain Engineering}

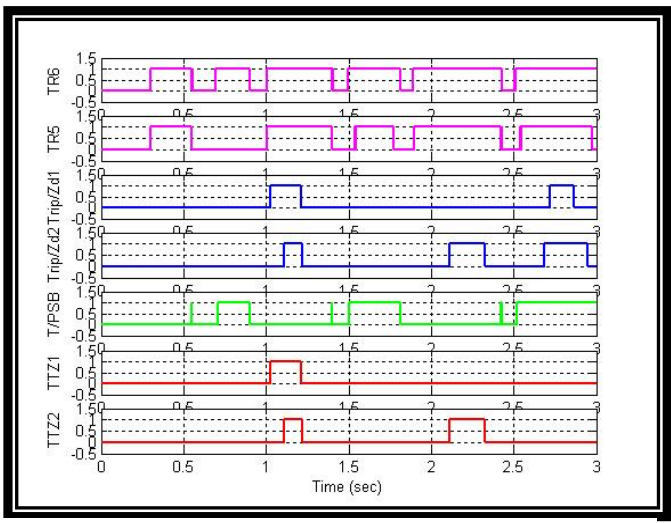

الشكل (17) تعاقب إصدار إثار ات الإفلات مع وجود الأعطال فى القطاعين الاول و الثانى
Vol.17 No.5

October 2009

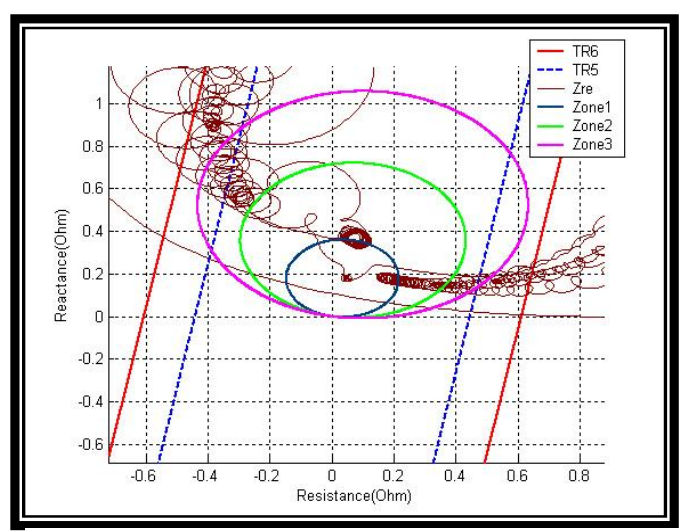

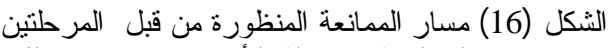

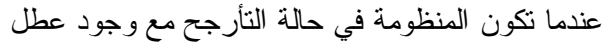

3-5: المنظومة في حالة التأرجح غير المستقر دون وجود عطل:

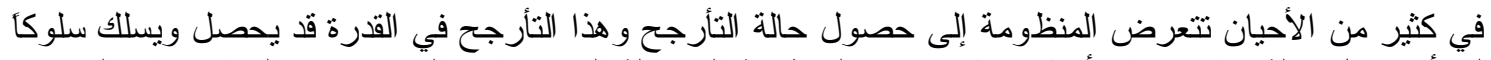

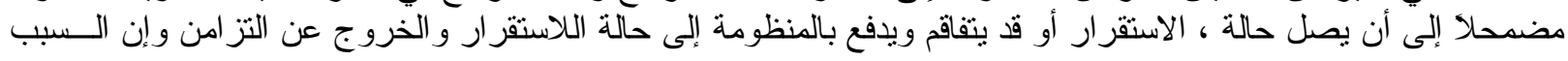

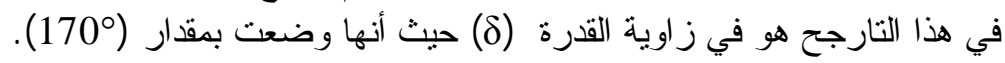

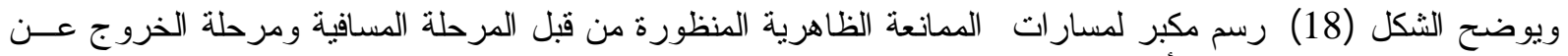

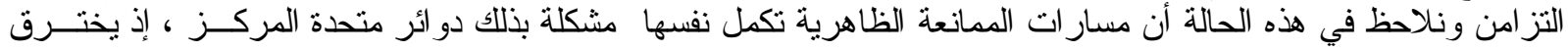

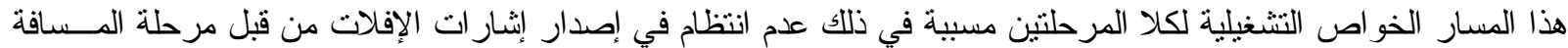

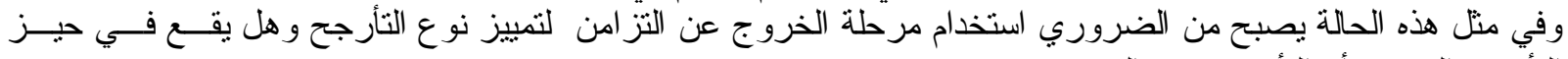

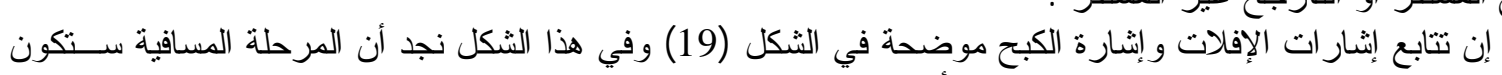

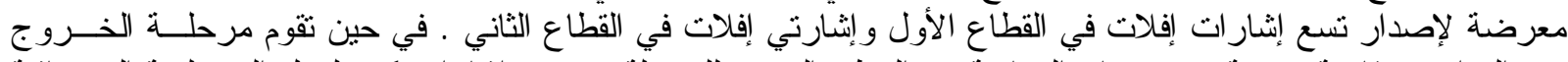

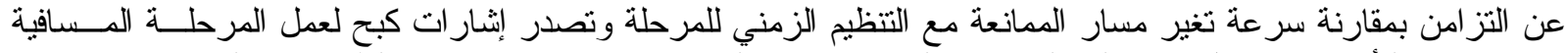

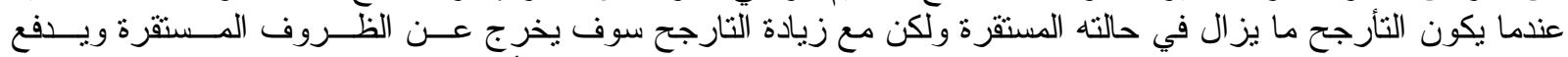

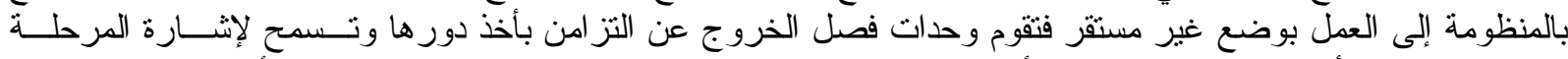

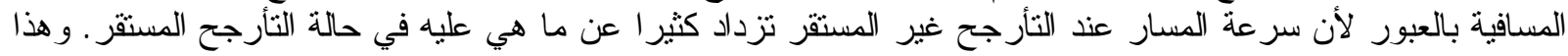

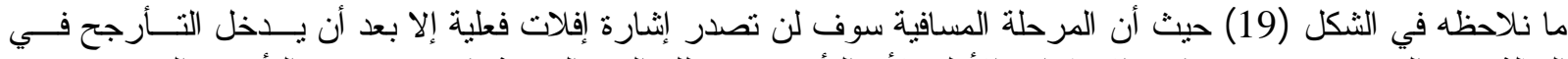
الحالة غير المستقرة في حين نكبح الإثارات الأولى لأن التأرجح في نلأك المدة الزمنية يكون في حيز التأرجح المسنقر.

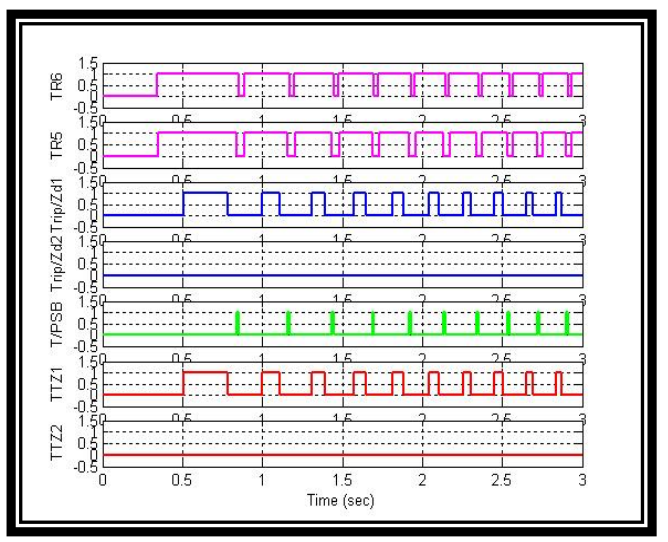

الثكل (19) نتابع إصدار إثارات الإفلات عند حصول حالة النأرجح غير المستقر في القدرة

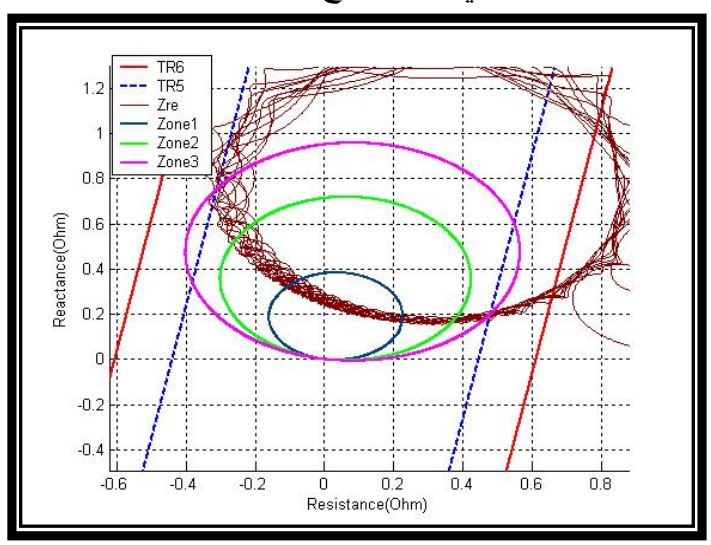

الثكل (18) يوضح مسار الممانعة الظاهرية عند حصول تأرجح غير مستقر في القدرة 


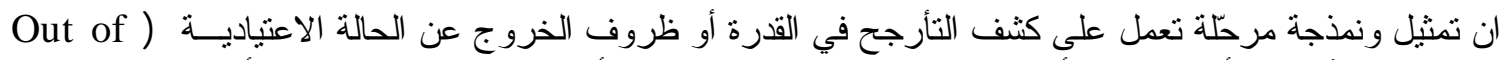
(Step Detection

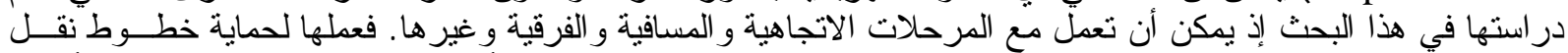

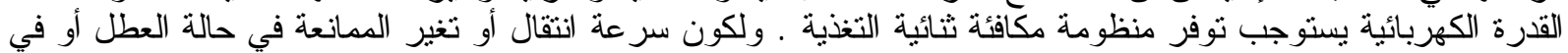

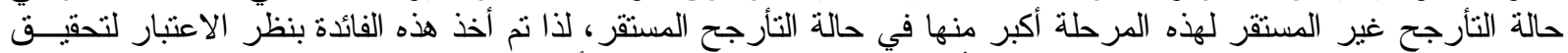

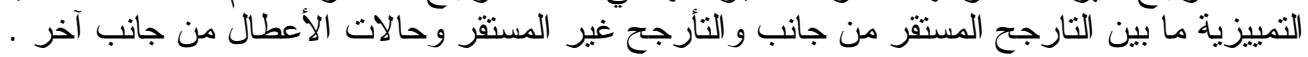

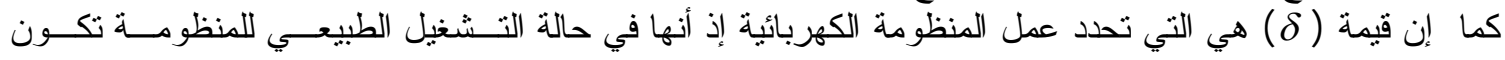
الز اوية بحدود (

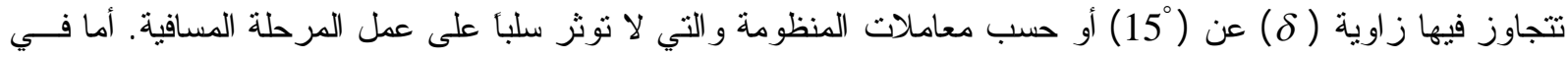
حالة تأرجح القدرة المستقر فتكون قيمة الزاوية (

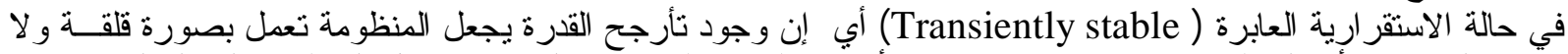

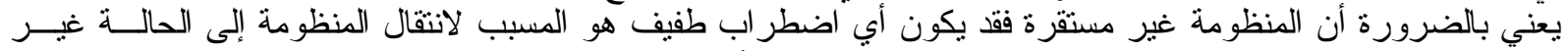

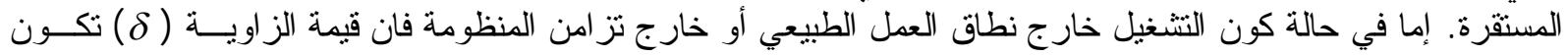

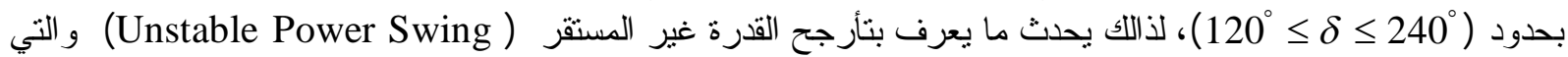

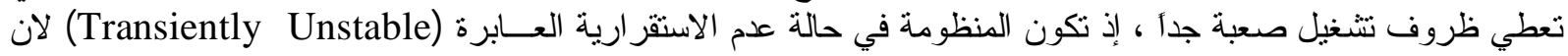

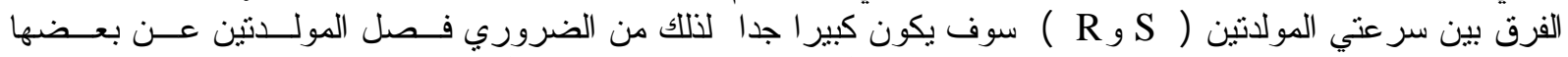
لصعوبة عملهما معا لتغذية الحمل بسبب فقدان التزامن (Loss of synchronism) مأ بينهما.

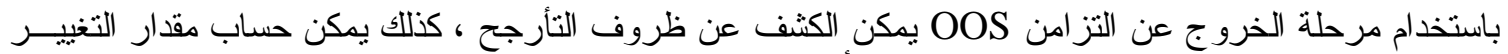

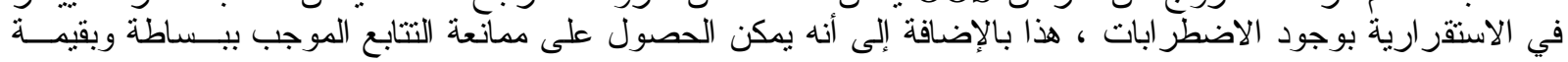

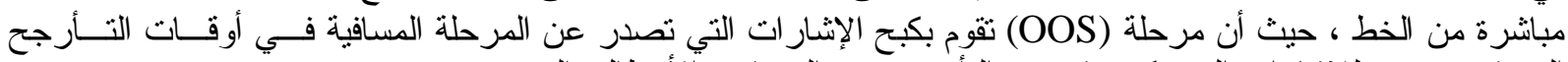

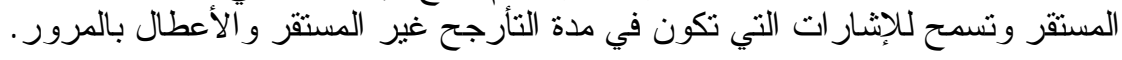

: 7 المصادر

[1] "Power Swing And Out-Of-Step Considerations Transmission Lines", A report to the Power System Relaying Committee Of the IEEE Power Engineering Society, 2005.

[2] D. Tziouvaras, and D. Dou, "Out-of-step protection fundamentals and advancements" , Schweitzer Engineering Laboratories, Inc. Boise, ID USA, 2003, [online]. Available at: http://www.selinc.com/techpprs/6163.pdf

[3] G. Benmouyal, D. Hou, and D. Tziouvaras, "Zero-setting Power Swing Blocking Protection", 31st Annual Western Protective Relay Conference, October 19-21, 2004, Spokane, Washingto.

[4] F. Plumptre, S. Brettschneider, Cegertec, A.J Hiebert, M. Thompson, "Validation of Out-ofStep Protection With a Real Time Digital Simulator" Electrical report, [online]. Available at: http://www.selinc.com .

[5] D. Hou, S. Chen, and S. Turner, "SEL-321-5 Relay Out-of-Step Logic," Schweitzer Engineering Laboratories, Inc. Application Guide AG97-13, July 23, 1997.

[6] Joe Mooney and Normann Fischer, "Application Guidelines for Power Swing Detection on Power Systems", Proceedings of the 32nd Western Protective Relay Conference, Spokane, WA, October 2005.

[7] Gerhard Ziegler, "Numerical Distance Protection, Principles and Application", Siemens,Erlangen,Publics-MCD-Verl.1999.

$$
\text { تم اجراء البحث في كلية الهندسة - جامعة الموصل }
$$

